\title{
Polos fríos en el Calar de Hernán Pelea y Cabrilla (Jaén, España), factores sinópticos y de microescala
}

Cold poles in Hernán Pelea and Cabrilla plateau (Jaén, Spain), synoptic and microscale factors

\author{
David Espín Sánchez \\ david.espin1@um.es \\ Departamento de Geografía \\ Universidad de Murcia (España) \\ Carmelo Conesa García \\ cconesa@um.es \\ Departamento de Geografía \\ Universidad de Murcia (España) \\ Jorge Olcina Cantos \\ jorge.olcina@ua.es \\ Departamento de Análisis Geográfico Regional y Geografía Física \\ Universidad de Alicante (España)
}

\section{Resumen}

Los extensos e inhóspitos calares ubicados en las Sierra de Segura y Cabrilla (divisoria entre las demarcaciones hidrográficas del Segura y Guadalquivir) presentan un estereotipo microclimático caracterizado por inviernos extremadamente fríos, con temperaturas mínimas absolutas cercanas 
a $-30^{\circ} \mathrm{C}$ en invierno, y $-10^{\circ} \mathrm{C}$ y $-15^{\circ} \mathrm{C}$ en otoño y primavera respectivamente. Los datos registrados han sido obtenidos de una red propia de termómetros registradores (datalogger) entre octubre de 2016 y febrero de 2021 (con un total de cinco inviernos de observación). A través del análisis estadístico de datos diezminutales y diarios de tres puntos de observación (Monterilla, Navalasno y Nava del Polvo), imágenes satelitales (VIIRS LST) y reanálisis mesoescalares es posible llevar a cabo la primera descripción climática del área de estudio, así como la identificación de los factores desencadenantes (sinópticos y de microescala) de las temperaturas mínimas extremas registradas, y el análisis de la tipología de los procesos de inversión térmica nocturna (ITN) y las piscinas de aire frío (CAP) generadas en el área de estudio. A pesar de que el tipo de piscina fría predominante es la de erosión turbulenta $(39,0 \%)$, los procesos de estabilidad nocturno son intensos $\left(\mathrm{C}_{\mathrm{INV}}\right.$ entre 7,6 y $\left.12,5^{\circ} \mathrm{C}\right)$.

Palabras clave: calar; inversión térmica; polo de aire frío; sierra de Segura; termómetro registrador.

\section{Abstract}

The large and inhospitable plateaus located in the Segura and Cabrilla mountain (the watershed between the Segura and Guadalquivir river basin), present a microclimatic stereotype characterized by extremely cold winters, with absolute minimum temperatures around to $-30^{\circ} \mathrm{C}$ in winter, and $-10^{\circ} \mathrm{C}$ and $-15^{\circ} \mathrm{C}$ in autumn and spring respectively. The data recorded has been obtained from its own network of thermometers (dataloggers) between october 2016 and march 2021 (with a total of five winter). Through the statistical analysis of data ten minutes and daily of three observation points (Monterilla, Navalasno and Nava del Polvo), satellite images (VIIRS LST), and mesoscale reanalysis, carry out the first climatic description of the study area is possible, as well as the identification of the triggering factors (synoptic and microscale) of the extreme minimum temperatures recorded, and the analysis of the typology of the inversion temperature nocturnal processes (ITN) and cold air pools (CAP) generated in the study area. Although the predominant type of cold pool is turbulent erosion $(39,0 \%)$, the nocturnal stability processes are intense (CINV between 7.6 and $\left.12.5^{\circ} \mathrm{C}\right)$.

Key words: plateau; temperature inversion; cold air pools; Segura mountain; recording thermometer. 


\section{Introducción}

El estudio de temperaturas mínimas extremas ha sido ampliamente analizado durante las últimas décadas, especialmente en áreas deprimidas montañosas. Es ahí donde aparecen piscinas de aire frío (CAP) que generan las temperaturas más bajas del planeta (Whiteman, 1986, 2001, 2004a, 2008; Eisenbach et al., 2003; Whiteman et al., 2004b; Pospichal et al., 2003).

Las CAP son deposiciones de aire más frío que su entorno inmediato (más denso), almacenadas en sectores topográficamente deprimidos (fondos de valle, poljés, dolinas[) durante madrugadas de estabilidad atmosférica (escaso viento y poca nubosidad). Se desarrollan, especialmente, durante las horas nocturnas por enfriamiento radiativo de la capa de aire que se encuentra en contacto con el suelo (Whiteman et al., 1997).

Desde hace más de 90 años los estudios de CAP se han desarrollado ampliamente en los Alpes austriacos, concretamente en el valle del Gstettneral, donde se registran temperaturas mínimas inferiores a $-50^{\circ} \mathrm{C}$ en fondos de dolinas (Schmidt, 1930). Se trata de uno de los registros de temperatura más bajos del continente europeo. Scherhag (1948) plantea los primeros criterios para la identificación de las CAP, identificando una baja cerrada en la troposfera media y alta (300-700 hPa), un campo de presión superficial definida, y un espesor geopotencial de $500 / 1000 \mathrm{hPa}$ con un contorno cerrado. Sauberer \& Dirmhirn (1956) determinan diferencias térmicas notables entre el fondo y el borde de las dolinas, donde los flujos en el interior son débiles y la prevalencia de vientos sinópticos no alcanza a los embolsamientos de aire frío de los fondos.

Litschauer (1962) aportó nuevas respuestas sobre los fenómenos de inversión térmica en sectores deprimidos de alta montaña. Anotó diferencias de entre 5 y $10^{\circ} \mathrm{C}$ de superficie nivosa a no nivosa. Además, propuso el índice de Sky view Factor (SvF) o porción de cielo visible para determinar el potencial de acumulación de frío nocturno estable en el interior de una dolina, en función de su fisonomía (más abierta o cerrada).

En las Montañas Rocosas de EE. UU. se han desarrollado numerosos análisis de eventos de inversiones térmicas asociadas a la génesis de temperaturas mínimas extremas, donde se corrobora que la dolina es la geoforma kárstica que registra las temperaturas más bajas en latitudes medias, con registros de hasta $-56^{\circ} \mathrm{C}$ en Peter Sink (Clements et al., 2003). Uno de los estímulos para la investigación de las CAP en áreas montañosas es servir de "cuenca piloto" para la mejor compresión de la formación y disipación de las CAP, que constituye uno de los problemas de predicción más difíciles en el oeste de los Estados Unidos (Smith et al., 1997), y 
un gran impacto climático en la contaminación del aire de las cuencas y valles densamente habitados (Petkovsek, 1992).

Diferentes análisis en ámbitos montañosos han explicado la influencia de los vientos catabáticos en las CAP, causados por un súbito enfriamiento de las áreas de drenaje de aire frío en los fondos de valle por contacto con las laderas, y que se aceleran al poseer una flotabilidad negativa (Barr \& Orgill, 1989; Neff \& King, 1989; Gudiksen et al., 1992). Además, se han estudiado las causas de la rotura de las CAP con la llegada del día, debido al crecimiento convectivo de la capa límite tras la salida del sol (Whiteman \& McKee, 1982) y a la erosión turbulenta del viento en niveles superiores de la CAP (Petkovsek, 1992; Vrhovec \& Hrabar, 1996). Las principales causas de las roturas son debidas a advecciones de aire frío (Zhong et al., 2001), el paso de frentes (Whiteman et al., 2001), o por la erosión turbulenta de la CAP (Zhong et al., 2003; Fritts et al., 2010). Dichas causas fueron profundizadas por Lareau et al. (2013) y Eisenbach et al. (2003), quienes realizan una clasificación de ocho patrones de CAP según la evolución sinóptica y la rotura del estrato de inversión térmica.

Han seguido desarrollándose análisis térmicos en Peter Sinks, en Utah, EE. UU. (Clements et al., 2003), en las dolinas austriacas del Gstettneralm (Pospichal et al., 2003; Whiteman et al., 2004) y en el Busa di Manna (2550 m), ubicado en la plataforma kárstica del Pale di San Martino (Trentino-Alto Adige, Italia), con una temperatura mínima absoluta de $-47,0^{\circ} \mathrm{C}$ (Renon, 2011).

Recientemente, se analiza la influencia del viento RACO en la formación de CAP en el Cajón del Maipo (Chile), a través de radiosondeos, SODAR y ceilómetros móviles (Muñoz \& Armi, 2020). O el análisis de las características de las CAP a través de cámaras térmicas (TIR) en la cuenca del Funtensee (Berchtesgaden Alps, Alemania) (Grudzielanek \& Fliegner, 2018)

También han sido relevantes las investigaciones enfocadas a la vinculación de grandes movimientos atmosféricos, como los vórtices polares de la tropopausa (TPVs), en la proliferación de CAP en el centro y este de Estados Unidos, donde los autores concluyen que existe un mayor porcentaje de CAP asociadas a TPV en las regiones del norte de los Estados Unidos (32,1 \%35,7\%) (Biernat et al., 2021).

El esfuerzo por comprender las características de las CAP para pronósticos más precisos ha llevado a una importante mejora con un desarrollo metodológico notable. En la cuenca del río Columbia se utilizan radiómetros de microondas, perfiladores de viento por radar y sistemas de sondeos acústicos (McCaffrey et al., 2019). 
Las nuevas metodologías propuestas para la clasificación de CAP han tenido un importante papel durante los últimos años, como destaca la investigación de Colegan et al. (2019), quienes utilizan el umbral de déficit de calor del valle (VHD) proporcionado por radiosondeos locales en el oeste de EE.UU.

En la Península Ibérica se registran temperaturas inferiores a $-30^{\circ} \mathrm{C}$ durante los últimos años, asociados a procesos de CAP y a la instalación de nuevos sensores en áreas remotas de alta montaña. En los Picos de Europa se registró una temperatura mínima de $-32,7^{\circ} \mathrm{C}$ (19 de febrero del 2016) en la Vega de Liordes $(1.880$ m), que constituye la temperatura mínima absoluta más baja registrada hasta el momento en la Península Ibérica (no validada por AEMET) (Iglesias González et al., 2018). Posteriormente, durante el mes de enero de 2021, el poljé de Liordes registró un nuevo récord de temperatura mínima absoluta con $-35.6^{\circ} \mathrm{C}$. Horas antes, se había registrado una temperatura mínima de $-34,1^{\circ} \mathrm{C}$ en el Tuc de La Llanca, en Baqueira Beret (Pirineo de Lleida) (Mucha, 2021).

La plataforma kárstica de Hernán Pelea y la Cabrilla (Jaén), el área de estudio, constituye un ámbito geográfico con las características típicas de las piscinas de aire frío. Establece el polo frío del interior del sureste de la Península lbérica, y muy probablemente de la mitad sur peninsular. Tal y como definió Renon (2011), las extensas superficies calizas, como el área de estudio, que conforma una extensa plataforma kárstica $\left(260,4 \mathrm{~km}^{2}\right)$, su elevada altitud media $(1690 \mathrm{~m})$, su casi completo cierre por elevaciones de $2000 \mathrm{~m}$ de altitud, y su compleja orografía (multitud de poljés, campos de lapiaces, y sistemas de dolinas) le confieren una serie de características que favorecen el enfriamiento:

- Una menor conductividad térmica, que limita el flujo de calor del terreno al estrato superficial.

- Una menor presencia de agua en el suelo y subsuelo, que garantiza una capacidad térmica realmente baja favoreciendo una enfriamiento más súbito y eficiente de la superficie, cuando es máxima la pérdida de radiación por onda larga.

- Una temperatura en el subsuelo sensiblemente inferior, por el efecto "refrigerante" del agua de infiltración que circula por las cavidades kársticas inferiores.

La investigación pretende analizar los procesos de inversión térmica nocturna (ITN) y las características de las temperaturas mínimas en los calares de Hernán Pelea y Cabrilla, debido principalmente a una motivación e interés de investigación climática en áreas poco conocidas a escala regional española, y porque son áreas que merecen un especial tratamiento en el marco del proceso actual de calentamiento global. 
Mediante la instalación de una red propia de termómetros registradores con datalogger, y la utilización de diversas herramientas mesoescalares y satelitales, se realiza un análisis detallado de las temperaturas mínimas (octubre 2016-febrero 2021). Además, el análisis de las piscinas de aire frío, donde se pone de relieve la intensidad de los procesos de inversión térmica, pretende ofrecer una visión más ajustada de los fríos inviernos que caracterizan el área de estudio.

\section{2 Área de estudio}

El extenso Calar de Hernán Pelea se localiza en la Sierra de Segura, al noreste de la provincia de Jaén. Se enmarca casi en su totalidad en el término municipal de Santiago-Pontones (Jaén), y un pequeño sector en los municipios de Castril (Granada) y Cazorla (Jaén). Constituye, la plataforma kárstica más extensa de la Península Ibérica $\left(144 \mathrm{~km}^{2}\right)$, con una altitud media de 1697 m de altitud. Los intensos procesos de ITN son potenciados por la orografía (gran cubeta aislada con picos de $2100 \mathrm{~m}$ de altitud), y a los numerosos campos de dolinas que lo caracterizan. Todo ello genera una recurrencia muy elevada de la aparición de hielo, nieve e intensas heladas.

Además, su gran pluviometría (con reiteradas nevadas) genera una importante disponibilidad de agua durante gran parte del año, que activa potentes procesos de gelifracción. Según la clasificación climática de Köppen pertenece a un área morfoclimática de tipo oceánicomediterránea de verano suave (Csb), aunque estudios recientes lo definen como un área de alta montaña de tipo mediterráneo frío subhúmedo de cimas prebéticas (Gómez Zotano et al., 2015, 2016). 
Figura 1. Localización del área de estudio y distribución de los termómetros registradores (dataloggers) utilizados

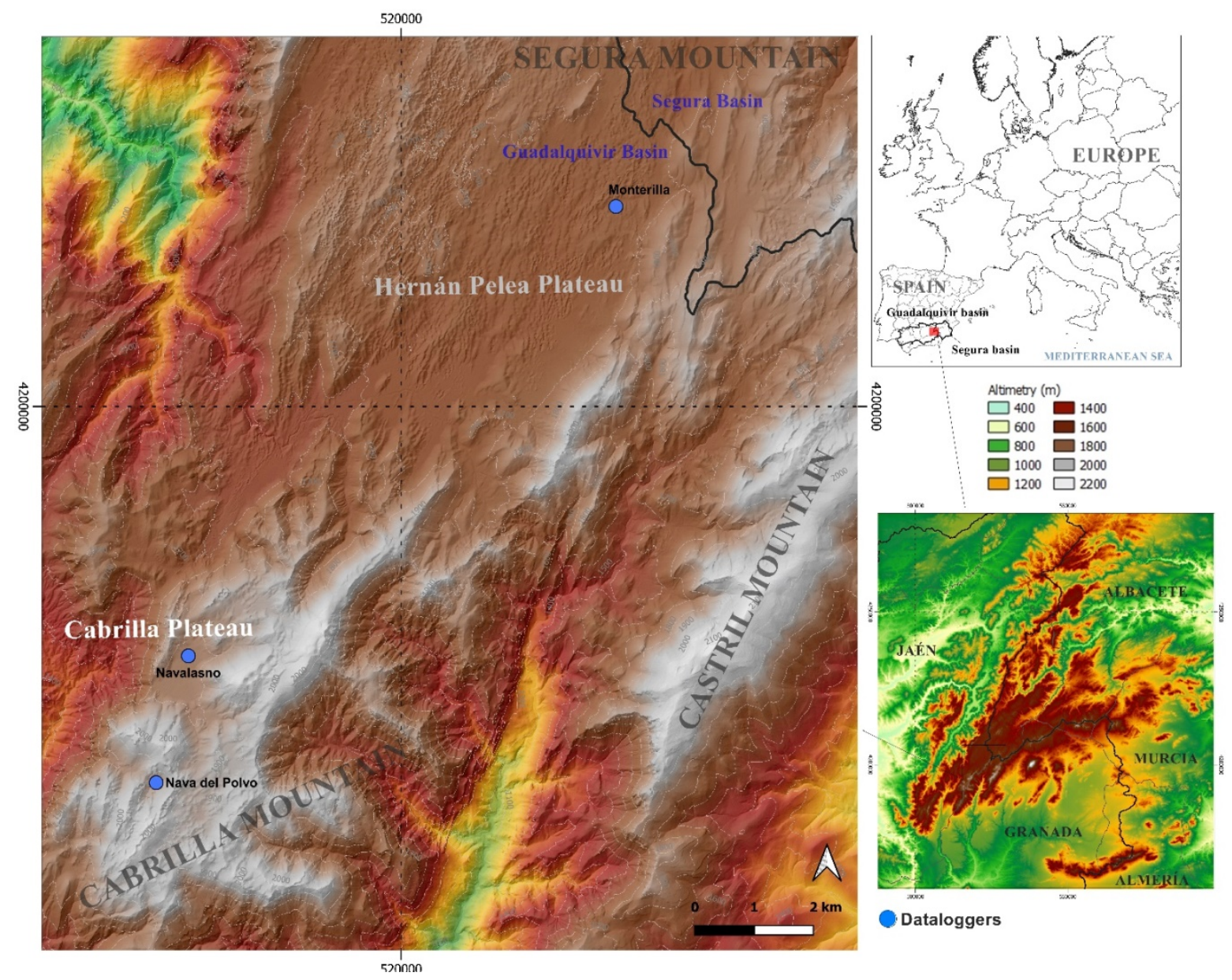

Fuente: elaboración propia

\section{Datos y métodos}

\subsection{Datos}

El análisis realizado utiliza datos diarios de temperaturas mínimas de una red propia de 3 termómetros registradores (datalogger) ubicados en el área de estudio (Figura 1). La toma de datos comprende un rango temporal desde octubre 2016 a febrero 2021. Abarca, por tanto, un total de 5 inviernos meteorológicos de observación (diciembre, enero y febrero), (Tabla 1).

Los termómetros registradores (dataloggers) utilizados son del tipo Microlite 32K (32 000 registros) y $\mathrm{HOBO}$ MX2301 de 50000 registros, ideados para climas severos (Figura 2). La garita meteorológica utilizada es la Davis 7714 (Monterilla), y para los termómetros ubicados en los parajes de Navalasno y Nava del Polvo dos garitas meteorológicas tipo pagoda, cedidas por la Agencia Estatal de Meteorología (AEMET) de la Delegación de Murcia y Málaga. 
Tabla 1. Registradores de temperatura (dataloggers)

utilizados desde octubre 2016 a febrero 2021

\begin{tabular}{|c|c|c|c|c|}
\hline PARAJE & MUNICIPIO & ALTITUD & PROTECCIÓN & SENSOR \\
\hline $\begin{array}{c}\text { Nava del Polvo- } \\
\text { Troncos }\end{array}$ & Cazorla & $1836 \mathrm{~m}$ & Pagoda AEMET & HOBO MX2301 \\
\hline Navalasno & Cazorla & $1770 \mathrm{~m}$ & Pagoda AEMET & Microlite 32K \\
\hline $\begin{array}{c}\text { Monterilla-Don } \\
\text { Fernando }\end{array}$ & Santiago-Pontones & $1660 \mathrm{~m}$ & Davis 7714 & HOBO MX2301 \\
\hline
\end{tabular}

Fuente: elaboración propia

La altura del sensor y la garita respecto a la superficie es de $2 \mathrm{~m}$ de altura, algo superior a la de los estándares oficiales de la OMM (2017), principalmente para evitar las importantes acumulaciones de nieve en invierno.

Los datalogger utilizados poseen una resolución temporal de medición diezminutal, con una precisión de $\pm 0,3^{\circ} \mathrm{C}$ y una resolución térmica de $0,1^{\circ} \mathrm{C}$. Los termómetros registradores ubicados en el área de estudio han sido calibrados por la Delegación Territorial de AEMET de Murcia, en el Centro Meteorológico Territorial de Guadalupe. Se ha determinado una desviación de $+0,2^{\circ} \mathrm{C}$ en las temperaturas mínimas. Los resultados expuestos en el análisis han sido corregidos con el calibrado realizado.

Los datos de temperatura horarios de los datalogger también han sido utilizados para identificar los diferentes tipos de piscinas de aire frío nocturno (CAP), desde el 1 diciembre 2016 al 29 febrero 2020.La información es complementada con datos de dirección y velocidad del viento, humedad relativa, nubosidad y temperatura de sondeos atmosféricos de Murcia - Guadalupe, así como de dos estaciones meteorológicas de montaña (Calar Alto-CAHA-Almería; Casas del Rey-Moratalla, Murcia, SIAM IMIDA). 
Figura 2. Ubicación de los sensores de temperatura: a) dolina de la Nava del Polvo (Calar de la Cabrilla) con sensor HOBO MX2301 en garita meteorológica de tipo Pagoda cedida por AEMET, b) pojé colgado de Navalasno, con sensor microlite 32K en garita meteorológica tipo Pagoda cedida por AEMET; y c) campo de dolinas de Monterilla con sensor HOBO MX25 en garita meteorológica tipo Davis 7714

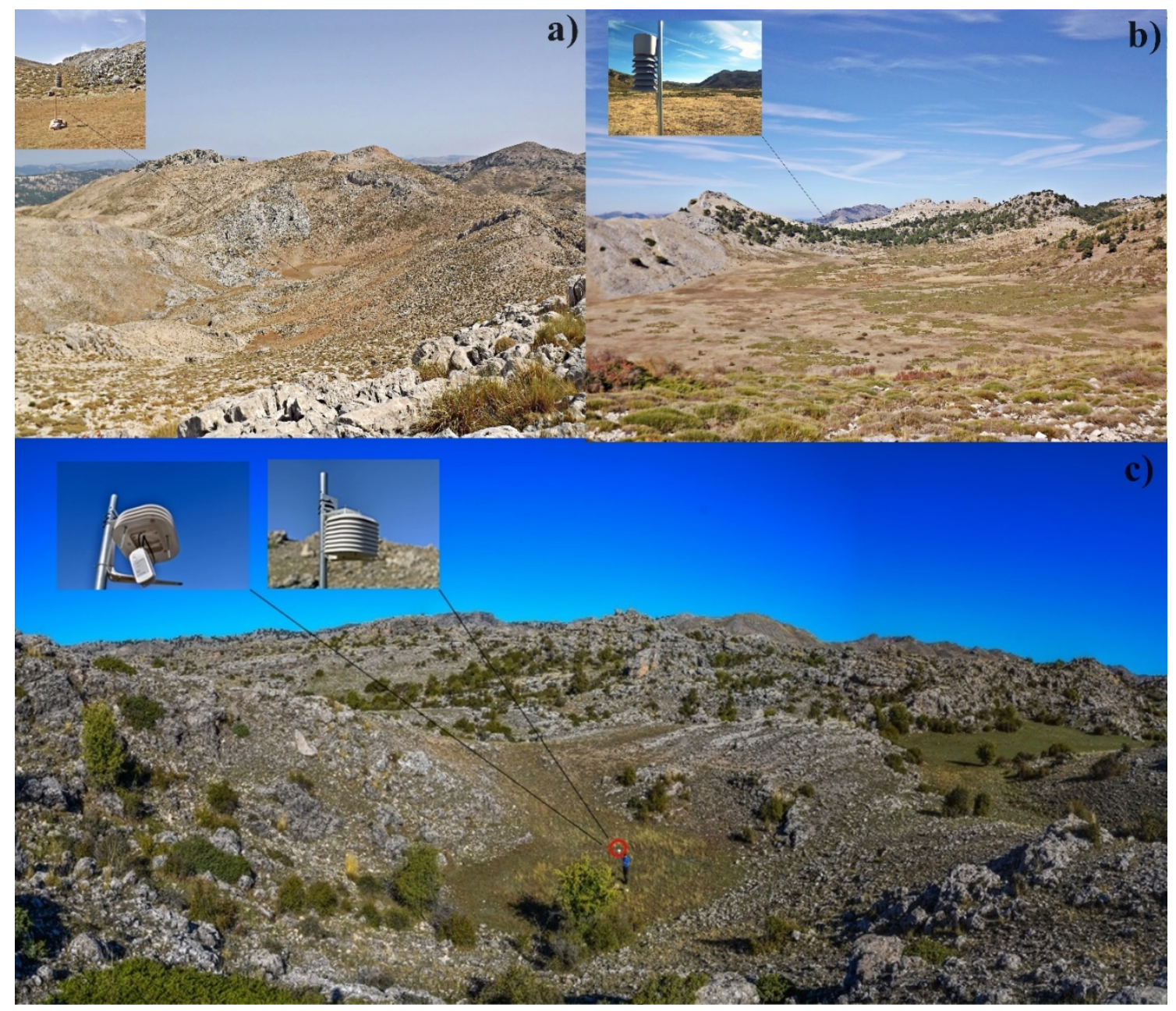

Fuente: elaboración propia

Se utilizan datos de sondeos atmosféricos nocturnos realizados desde el Centro Meteorológico Territorial de Guadalupe - Murcia (AEMET) a las OO UTC (1 de diciembre de 2016 al 28 de febrero de 2020). Se analizan las variables meteorológicas (temperatura, humedad relativa, dirección y velocidad de viento) registradas en cada datalogger a través de sondeos atmosféricos nocturnos. También son analizados los datos de reanálisis atmosférico en diferentes niveles geopotenciales $(300,500,700$ y $850 \mathrm{hPa}$ ), así como el campo de presión atmosférica superficial. Concretamente, se obtiene una cartografía promedio para los diferentes tipos de CAP obtenida del NCEP I| Reanalysis, cuya fuente de datos es el modelo estadounidense del Global Forecast System (GFS) (http://www.esrl.noaa.gov/psd/) (NOAA/ESRL Physical 
Sciences Division, Boulder, Colorado). Además, se obtienen datos de reanálisis atmosférico en la web (http://www.eumetrain.org/ePort_MapViewer/index.html) para los campos de presión de los geopotenciales de 300 y $850 \mathrm{hPa}$.

Finalmente, las trayectorias y procedencias de las masas de aire que afectan al área de estudio durante las jornadas analizadas de CAP son obtenidas del reanálisis del HYSPLIT (NOAA) (https://www.ready.noaa.gov/hypub-bin/trajtype.pl?runtype=archive).

Por otra parte, los productos satelitales del MODIS-TERRA (Corrected Reflectance 3-6-7), para la estimación de la superficie nivosa (SMAP_L4_Snow_Mass), y las termografías generadas obtenidas del producto "Brightness Temperature (Band I5, Night)", del satélite VIIRS (SUOMI), se obtienen en su web (https://worldview.earthdata.nasa.gov/).

\subsection{Métodos}

Los datos de temperatura diezminutales y los diarios de temperatura mínima absoluta de la red de datalogger son utilizados para el cálculo de diferentes índices climáticos en invierno, tales como días de helada (FD), temperaturas mínimas absolutas (TNn), temperatura media de las mínimas (TNm), primer día de helada del periodo (FFF), último día de helada del periodo (LSF), longitud del periodo de heladas (FP), horas de helada y distribución térmica horaria anual.

Además, para conocer de forma más detallada el potencial frío del área de estudio, es imprescindible conocer la caída de la temperatura tras la puesta de sol en madrugadas estables. Para ello se propone la tasa de enfriamiento (TE). Dicho índice contabiliza la variación de la temperatura durante las primeras horas de la tarde-noche (Eq. 1), concretamente entre las $16 \mathrm{~h}$ UTC (con insolación) y las 19 h UTC (sin insolación directa).

$$
\mathrm{TE}=\mathrm{T}(16 \mathrm{~h})-\mathrm{T}(19 \mathrm{~h})
$$

donde T es la temperatura $\left({ }^{\circ} \mathrm{C}\right)$ tomada a las $16: 00 \mathrm{~h}$ y $19: 00 \mathrm{~h}$ UTC

La capacidad de inversión térmica $\left(\mathrm{C}_{\mathbb{I N V}}\right)$ es aplicada con el fin de determinar el grado de intensidad de los procesos de ITN en el área de estudio (Eq. 2):

$$
C_{\text {INV }}=T_{\text {GEOP }}(\text { i) }-\mathrm{TS} \text { (i) }
$$

donde $\mathrm{TZ}_{\mathrm{GEOP}}$ (i) es la temperatura geopotencial a la altitud de la estación meteorológica $\left({ }^{\circ} \mathrm{C}\right)$ proporcionada por el sondeo atmosférico (00 h), y Ts (i), la temperatura superficial de la estación meteorológica en $\left({ }^{\circ} \mathrm{C}\right)$. 
El estudio de la estabilidad atmosférica analizada en los episodios de tipos de CAP, y en aquellos más relevantes del periodo de estudio, se lleva a cabo a través de las clases de estabilidad de Pasquill (1961), calculadas con la profundidad de la capa límite (Zi), y el coeficiente de mezcla vertical $(\mathrm{Kz})$.

Tabla 2. Condiciones atmosféricas (clases de estabilidad)

\begin{tabular}{|c|c|c|c|c|c|}
\hline \multicolumn{4}{|c|}{ INSOLACIÓN (DÍA) } & \multicolumn{2}{c|}{ CONDICIONES NEUTRAS } \\
\hline VV (m/s) & Fuerte & Moderada & Débil & $>4 / 8$ octas nubes & $<=4 / 8$ octas nubes \\
\hline$>2$ & A & A-B & B & E & F \\
\hline $2-3$ & A-B & B & C & E & F \\
\hline $3-5$ & B & B-C & C & D & D \\
\hline $5-6$ & C & C-D & D & D & D \\
\hline$>6$ & C & D & D & D & \\
\hline
\end{tabular}

Leyenda: A: Extremadamente inestable; B: Moderadamente inestable; C: Ligeramente inestable; D: Condiciones neutras; E: Ligeramente estable; F: Moderadamente estable y G: Extremadamente estable

Fuente: Pasquill (1961)

La profundidad de la capa límite (Zi) es la distancia desde la superficie hasta un punto donde la velocidad del flujo ha alcanzado esencialmente la velocidad de 'flujo libre' (Prandtl, 1904). Es el espesor de la atmósfera en que se difunden (se mezclan) los contaminantes. Viene definido por la influencia que tiene el substrato geográfico en la intensidad del viento, advección de calor y humedad y grado de calentamiento o enfriamiento del suelo. Durante el día, el aporte de calor y la consiguiente mezcla vertical del aire incrementan el grosor de la capa límite, que alcanza su máxima altura a primeras horas de la tarde; por el contrario, durante la noche el enfriamiento del suelo impide la turbulencia y el espesor se reduce.

El coeficiente de mezcla vertical $(\mathrm{Kz})$ es una medida de la mezcla turbulenta dentro de la capa límite, utilizando el modelo de transporte y dispersión HYSPLIT (NOAA) para calcular el movimiento vertical de los contaminantes. La interacción de ambas o estabilidad atmosférica depende de la diferencia de temperatura entre una porción de aire y el aire que la rodea. Da lugar a 7 clases de estabilidad nocturna (Tabla 2).

La tipología de CAP está basada en la clasificación de Dorninger et al. (2011), quienes establecen ocho tipos según la evolución de la temperatura nocturna (1 evolución inalterada, 2 
formación tardía, 3 rotura temprana, 4 evento de mezcla, 5 perturbación alta, 6 perturbación baja, 7 erosión turbulenta, 8 ventana de inversión). Además, se identifican algunos episodios de piscinas de aire frío persistentes (PCAP), aquellas donde la temperatura de los fondos de valle o depresiones permanece por debajo de las registradas en altitudes superiores durante varios días (Whiteman et al., 2001).

Finalmente, el coeficiente de correlación de Kendall (Kendall, 1938) es utilizado para el análisis estadístico del apartado (5.5), con diferentes niveles de significancia (p-value) de 0.001 (***), $0.01(* *)$ y $0.05(*)$.

\section{Resultados}

\subsection{Singularidad climática de los calares: extremos muy fríos}

Una de las características principales del Calar de Hernán Pelea es la gran persistencia de los días de helada de manera consecutiva, que conforman, muy a menudo, periodos de heladas muy largos. Se contabilizan, en el periodo de análisis, un promedio de 13 episodios de al menos 3 heladas consecutivas por periodo frío. Los resultados obtenidos muestran una mayor longitud e intensidad durante los meses de diciembre, enero y febrero. Aunque el mayor número de episodios aparece en el mes de marzo, con un promedio de 8 episodios

Figura 3. Temperaturas mínimas absolutas mensuales $\left({ }^{\circ} \mathrm{C}\right)$ en el área de estudio (2016-2021)

\begin{tabular}{|c|c|c|c|c|c|c|}
\hline & \multicolumn{2}{|c|}{ Nava del Polvo } & \multicolumn{2}{|c|}{ Navalasno } & \multicolumn{2}{|c|}{ Monterilla } \\
\hline & \multicolumn{2}{|c|}{$1836 \mathrm{~m}$} & \multicolumn{2}{|c|}{$1770 \mathrm{~m}$} & \multicolumn{2}{|c|}{$1660 \mathrm{~m}$} \\
\hline Mes & $\mathrm{TNn}\left({ }^{\circ} \mathrm{C}\right)$ & Fecha & $\mathrm{TNn}\left({ }^{\circ} \mathrm{C}\right)$ & Fecha & $\mathrm{TNn}\left({ }^{\circ} \mathrm{C}\right)$ & Fecha \\
\hline Enero & -28.8 & $12 / 01 / 2021$ & -15.8 & $18 / 01 / 2017$ & -25.4 & $12 / 01 / 2021$ \\
\hline Febrero & -23.2 & $05 / 02 / 2018$ & -15.5 & $09 / 02 / 2018$ & -24.2 & $05 / 02 / 2018$ \\
\hline Marzo & -16.4 & $22 / 03 / 2018$ & -11.3 & $22 / 03 / 2018$ & -16.7 & $22 / 03 / 2018$ \\
\hline Abril & -7.5 & 02/04/2017 & -4.8 & $01 / 04 / 2018$ & -7.9 & $02 / 04 / 2017$ \\
\hline Mayo & -6.0 & $02 / 05 / 2018$ & -4.6 & $02 / 05 / 2018$ & -6.3 & $02 / 05 / 2018$ \\
\hline Junio & -2.6 & 06/06/2019 & -0.7 & 06/06/2019 & -2.1 & 06/06/2019 \\
\hline Julio & 0.1 & 01/07/2017 & 2.3 & 01/07/2017 & -0.3 & 01/07/2017 \\
\hline Agosto & 1.0 & $30 / 08 / 2020$ & 1.6 & $30 / 08 / 2020$ & 2.3 & $30 / 08 / 2020$ \\
\hline Septiembre & -2.1 & $16 / 09 / 2017$ & 0.2 & $16 / 09 / 2017$ & -3.1 & $17 / 09 / 2017$ \\
\hline Octubre & -6.7 & $16 / 10 / 2020$ & -4.6 & $29 / 10 / 2018$ & -6.8 & $16 / 10 / 2020$ \\
\hline Noviembre & -9.7 & $21 / 11 / 2017$ & -6.9 & $19 / 11 / 2019$ & -9.6 & $21 / 11 / 2017$ \\
\hline Diciembre & -23.4 & $13 / 12 / 2017$ & -13.5 & $02 / 12 / 2017$ & -20.1 & $13 / 12 / 2017$ \\
\hline TNn Abs. $\left({ }^{\circ} \mathrm{C}\right)$ & -28.8 & $12 / 01 / 2021$ & -15.8 & 18/01/2017 & -25.4 & $12 / 01 / 2021$ \\
\hline
\end{tabular}

Fuente: elaboración propia

La distribución estadística de las temperaturas mínimas diarias muestra los valores más bajos de mediana y media aritmética en Monterilla y Nava del Polvo, con una temperatura de $1,2^{\circ} \mathrm{C}$, 
mientras que Navalasno registra una temperatura media de las mínimas de $2,8^{\circ} \mathrm{C}$. Los cuartiles y los percentiles más bajos en los dos ámbitos más fríos son realmente destacables, con un rango térmico normal (P25/P75) entre $-2,7^{\circ} \mathrm{C} / 2,9^{\circ} \mathrm{C}$ y 5,9/6,3 $3^{\circ} \mathrm{C}$. Los valores térmicos más extremos vienen representados por $-6,2^{\circ} \mathrm{C}$ y $-6,7^{\circ} \mathrm{C}$ para el $\mathrm{P} 10$ y $-8,8$ y $-9.4^{\circ} \mathrm{C}$ para el $\mathrm{P} 5$, respectivamente (Figura 4).

Figura 4. Diagrama de cajas o boxplot de las temperaturas mínimas diarias $\left({ }^{\circ} \mathrm{C}\right)$ (de octubre 2016 a febrero 2021)

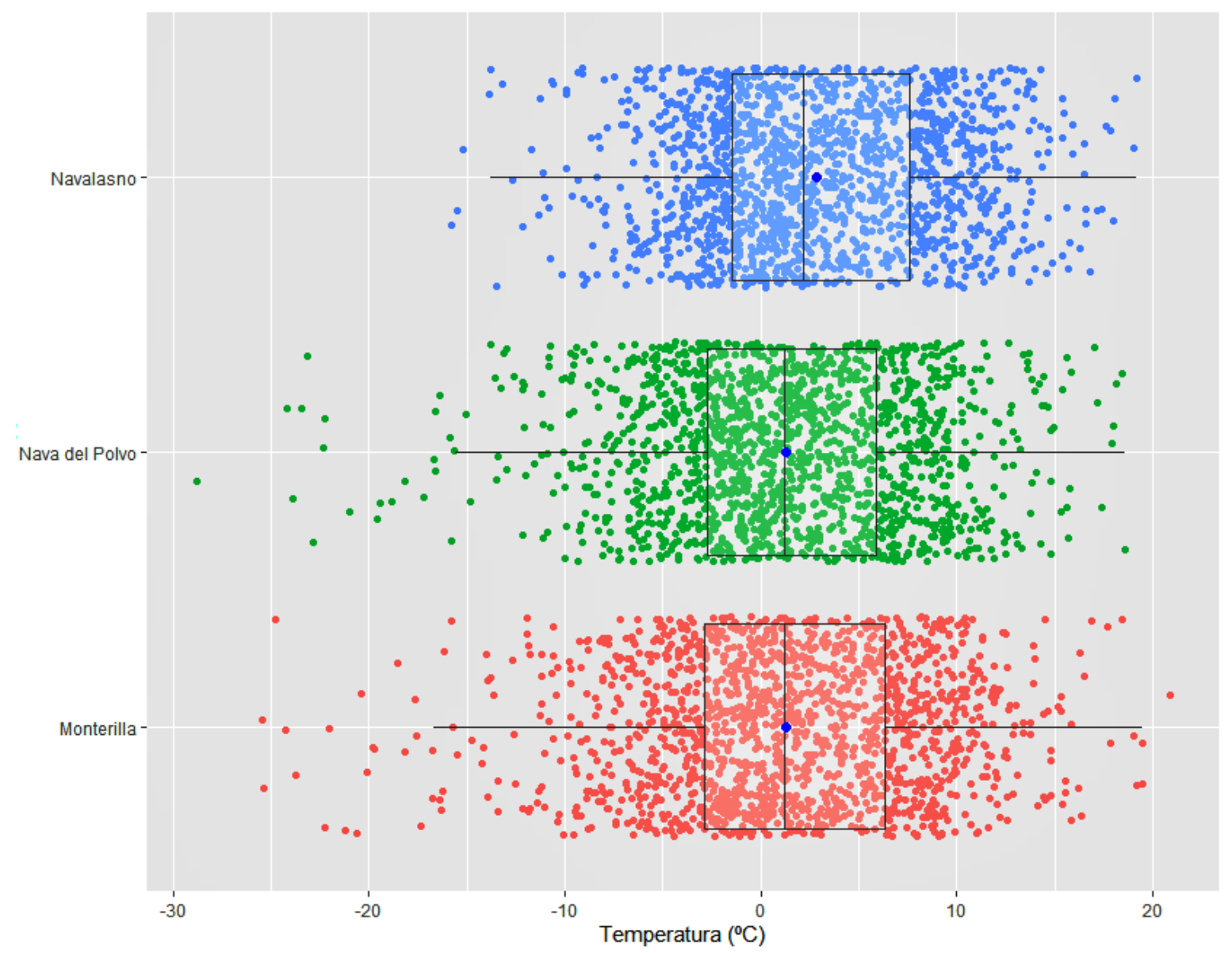

Nota: El punto azul hace referencia a la media aritmética.

Fuente: elaboración propia

El análisis mensual, y especialmente el promedio invernal, deja registros muy destacados en el área de estudio, con una media aritmética de las temperaturas mínimas de $-4,6^{\circ} \mathrm{C}$ y $-5.0^{\circ} \mathrm{C}$ durante el invierno. En los cinco periodos invernales de análisis, el trimestre invernal 17/18 es el que registra las temperaturas medias de las mínimas más bajas en el área de estudio, con registros especialmente relevantes en Monterilla y Nava del Polvo $\left(-7,6\right.$ y $-6,6^{\circ} \mathrm{C}$ respectivamente). 
El sistema exokárstico de Monterilla y Nava del Polvo ha registrado valores muy bajos en tan sólo 5 inviernos de observación, con registros inferiores a $-20^{\circ} \mathrm{C}$ (Figura 5). Las temperaturas mínimas registradas en Nava del Polvo $\left(-28,8^{\circ} \mathrm{C}\right.$ el 12 de enero de 2021$)$ y Monterilla $\left(-25,4^{\circ} \mathrm{C}\right.$ el 12 de enero de 2021) suponen uno de los valores de temperatura más baja registrados desde que hay datos observacionales en la mitad sur peninsular. Por término medio, en los cinco inviernos de observación, el paraje de La Nava del Polvo registra una temperatura media de las mínimas absoluta de $-19,9^{\circ} \mathrm{C}$, y en Monterilla de $-18,5^{\circ} \mathrm{C}$. Los registros son muy notables al compararlos con observatorios meteorológicos cercanos de AEMET, como el de Pontones (7045), donde la temperatura media de las mínimas absolutas al año es de $-11,9^{\circ} \mathrm{C}$.

También es preciso destacar las heladas registradas durante el periodo estival en el área de estudio. El paraje de Monterilla registró una temperatura mínima de -0,3ㄷ el 1 de julio de 2017.

El número total de días de helada (FD) destaca especialmente en el área de estudio, donde Monterilla y Nava del Polvo registran un valor medio de 151,3 y 150,5 heladas anuales, respectivamente, con un pico destacado de 172 heladas durante el periodo frío 2016/2017 en el paraje de Monterilla. Casi la mitad de heladas (algo más de 75 heladas) se registran en el trimestre invernal (Figura 5), lo que supone un 85,1\% de madrugadas con temperaturas negativas. Resulta notable que la otra mitad se registre entre otoño y primavera. Por contextualizar el dato total, se trata de un registro superior al promedio registrado en dos observatorios meteorológicos de 1er orden de AEMET, como el de Navacerrada (135,4 heladas) o en Molina de Aragón $(117,0)$. Del mismo modo, observatorios meteorológicos de AEMET de capitales de provincia de Castilla y León promedian registros de 83,8 heladas en Soria, 76,0 en Valladolid o 71,4 en León.

El total de horas de helada (HE) y la ratio por día de helada son índices fundamentales para cuantificar el grado de persistencia de las temperaturas negativas durante una madrugada de helada. Los valores más elevados superan las 1700 horas de helada al año. Monterilla con 1839 horas, o Nava del Polvo con 1754 llegan a registrar un valor medio de entre 10,8 y 11,2 horas por día de helada. 
Figura 5. Temperaturas medias de las mínimas diarias $\left({ }^{\circ} \mathrm{C}\right)$ (izquierda), temperaturas mínimas absolutas $\left({ }^{\circ} \mathrm{C}\right)$ (centro) y número total del día de heladas (derecha) de Nava del

Polvo, Navalasno y Monterilla. Rango mensual (de octubre 2016 a febrero 2021) y periodos invernales $(16-17,17-18,18-19,19-20$ y $20-21)$

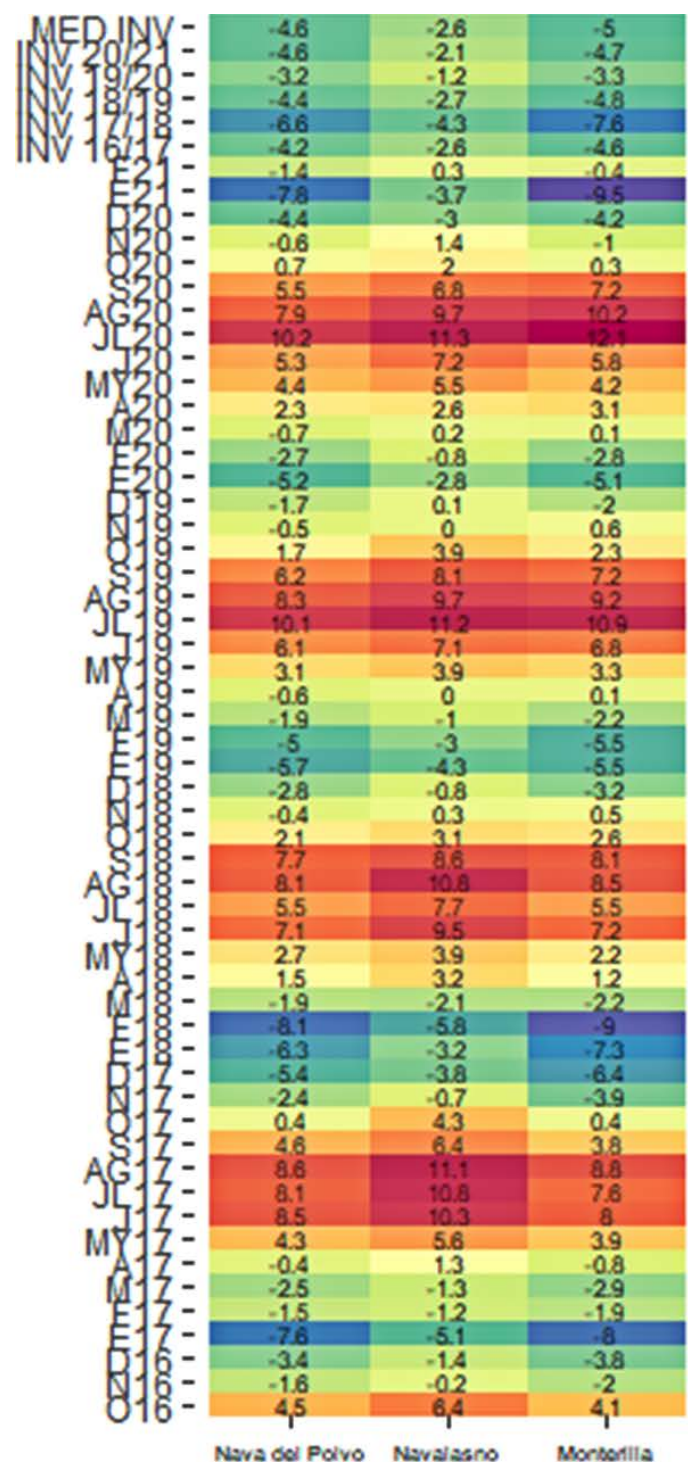

Dataloggers

$\mathrm{TNm}$

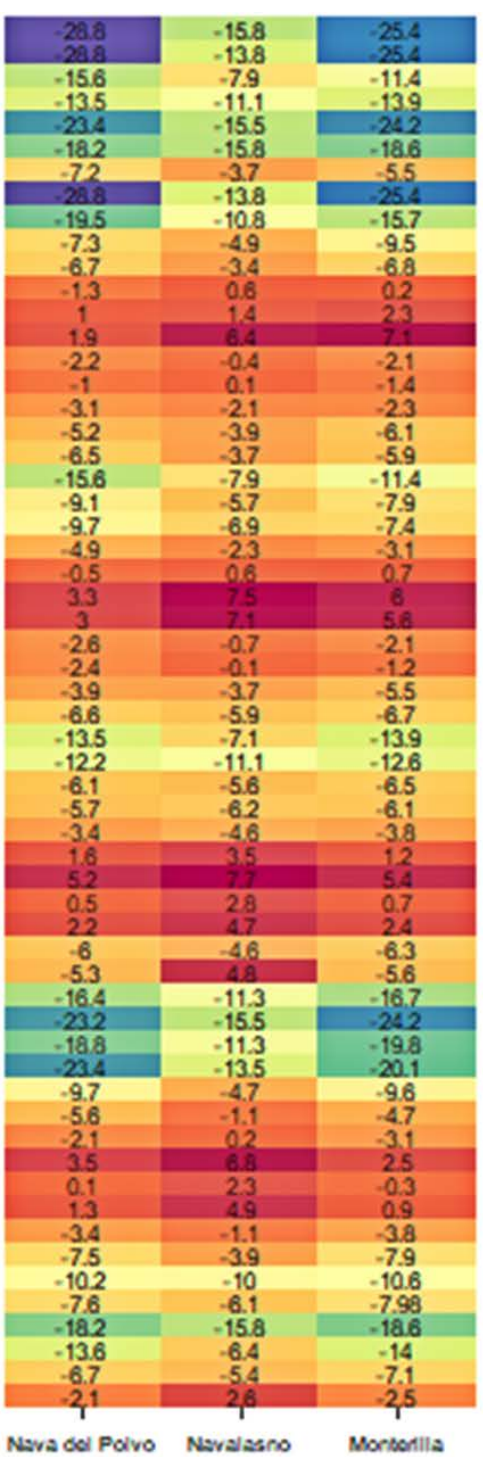

Datalogger

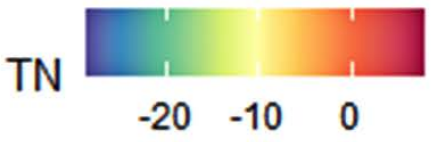

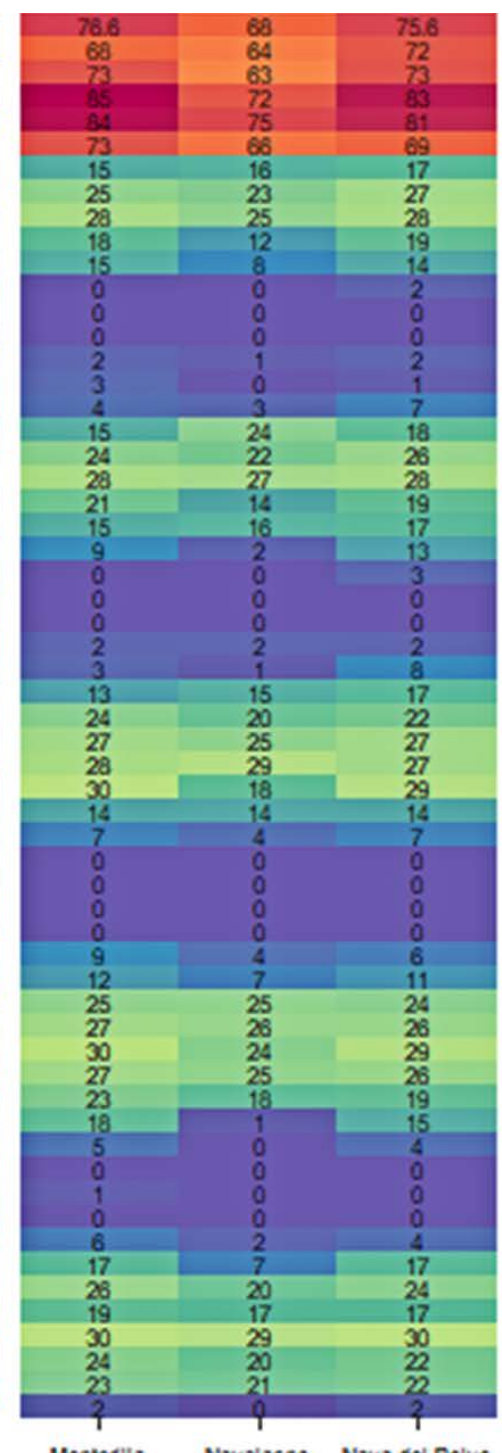

Datalogger

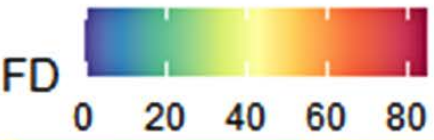

Fuente: elaboración propia

La tasa de enfriamiento (TE), tras la conformación de una CAP, es clave para cuantificar la capacidad de descenso térmico con la llegada de las horas nocturnas. El índice TE permite comparar de forma homogénea la caída de la temperatura durante las tres primeras horas de la tarde-noche, momento en que la velocidad de enfriamiento es la más importante (Dorninger et 
al., 2011). La TE en Monterilla, Nava del Polvo o Navalasno se sitúan entre 3,4 y 4,1 ${ }^{\circ} \mathrm{C}$. Las tasas de enfriamiento absoluto más importantes llegan a alcanzar valores ligeramente superiores a $16^{\circ} \mathrm{C}$ en 3 horas. En el paraje de Monterilla, durante la jornada del 28 de julio de 2017, se produce un descenso de $16,2^{\circ} \mathrm{C}$ en 3 horas, con una reducción desde $30,2^{\circ} \mathrm{C}$, a las $17.00 \mathrm{~h}$ UTC, a $14,0^{\circ} \mathrm{C}$, a las $20.00 \mathrm{~h}$ UTC. Se trata, por tanto, de lugares con un gran potencial de frío durante madrugadas estables de inversión térmica nocturna (Tabla 3).

La $C_{\text {INV }}$ promedio en el área de estudio muestra valores realmente destacados a lo largo del año $\left(8,1\right.$ a $\left.10,9^{\circ} \mathrm{C}\right)$. El paraje de Monterilla registra el valor más elevado el 17 de enero de 2018 $\left(26,3^{\circ} \mathrm{C}\right)$. Durante dicha madrugada (00 h UTC), se registra una temperatura mínima de $-13,6^{\circ} \mathrm{C}$ en el sensor de temperatura, mientras que el sondeo atmosférico de Murcia (OO h UTC) detecta una temperatura de $12,7^{\circ} \mathrm{C}$ a $1660 \mathrm{~m}$ de altitud (masa de aire muy templada para invierno).

El área de estudio arroja un periodo de heladas (FP), por lo general, muy extenso (Tabla 3). El paraje de Monterilla vuelve a registrar los valores más elevados y sorprendentes, con un periodo de heladas que se extiende, por término medio, del 6 de octubre al 12 de junio. Supone, por tanto, un total de 249,9 días (un 68,5 \% del año), y un periodo libre de heladas de sólo 115,1 días. Además, Monterilla, cuenta con la racha de heladas consecutivas más extensa del periodo analizado (48 días entre los meses de enero y febrero de 2018). La Figura 6 muestra la intensidad de la helada en los parajes de Nava del Polvo y Monterilla. 
Tabla 3. Valores de diferentes índices de los tres parajes analizados

\begin{tabular}{|c|c|c|c|}
\hline INDICES & NAVA DE POLVO & NAVALASNO & MONTERILLA \\
\hline $\mathrm{N}^{\circ}$ horas helada promedio (anual) & 1754,2 & $1528 ., 1$ & 1839,6 \\
\hline № horas helada promedio (invierno) & 1103,5 & 965,8 & 1141,9 \\
\hline № horas helada / día de helada (anual) & 11,2 & 11,8 & 10,8 \\
\hline Nºras helada / día de helada (invierno) & 13,6 & 12,9 & 13,6 \\
\hline Tasa de enfriamiento promedio (anual) & 3,4 & 4,2 & 4,1 \\
\hline Tasa de enfriamiento promedio (invierno) & 1,7 & 3,0 & 2,7 \\
\hline Tasa de enfriamiento absoluto (anual) & 10,5 & 12,5 & 16,2 \\
\hline Tasa de enfriamiento absoluto (invierno) & 8,7 & 12,5 & 13,9 \\
\hline Capacidad de inversión promedio (anual) & 9,4 & 8,1 & 10,9 \\
\hline $\begin{array}{l}\text { Capacidad de inversión promedio } \\
\text { (invierno) }\end{array}$ & 9,0 & 7,7 & 10,3 \\
\hline Capacidad de inversión absoluta (anual) & 24,2 & 16,7 & 26,3 \\
\hline Capacidad de inversión absoluta (invierno) & 24,2 & 16,7 & 26,3 \\
\hline Primera helada del periodo de heladas & 26 septiembre & 22 octubre & 6 octubre \\
\hline Última helada del periodo de heladas & 2 junio & 30 mayo & 12 junio \\
\hline Longitud del periodo de heladas (días) & 248,9 & 220,0 & 249,9 \\
\hline $\begin{array}{l}\text { Racha más larga de heladas consecutivas } \\
\text { ( }{ }^{\circ} \text { días) }\end{array}$ & $\begin{array}{c}47(11 / 01 / 18 \text { al } \\
26 / 02 / 18)\end{array}$ & $\begin{array}{l}28(28 / 12 / 19 \\
\text { al } 24 / 01 / 20)\end{array}$ & $\begin{array}{l}48(11 / 01 / 18 \\
\text { al } 27 / 02 / 18)\end{array}$ \\
\hline
\end{tabular}

Fuente: elaboración propia

El paraje de Monterilla, durante el periodo de análisis, registra 38328 datos horarios. Para contextualizar la magnitud fría del paraje, las temperaturas inferiores a $0^{\circ} \mathrm{C}$ representan el $17,5 \%$ del periodo de observación, con un total de 6707 horas, o lo que viene a representar 279 días completos. Incluso, los registros inferiores a $-2^{\circ} \mathrm{C}$ ostentan un peso relativo muy importante, con un 10,1\% del periodo de análisis (3871,1 horas en total). Los registros extremos de temperatura $\left(<-10^{\circ} \mathrm{C}\right)$ totalizan un menor número de horas, aunque notable: 306 horas. Se anota, además, un total de 76,6 horas con temperatura igual o inferior a $-15^{\circ} \mathrm{C}$, y hasta 38,3 horas para el umbral de $-20^{\circ} \mathrm{C}$. 
Figura 6. Evolución diaria de la intensidad de helada $(\mathrm{IH})$ en Nava del Polvo (Cabrilla) (izquierda) y Monterilla (Hernán Pelea (derecha), desde el 1 de octubre de 2016 al 28 de febrero de 2021
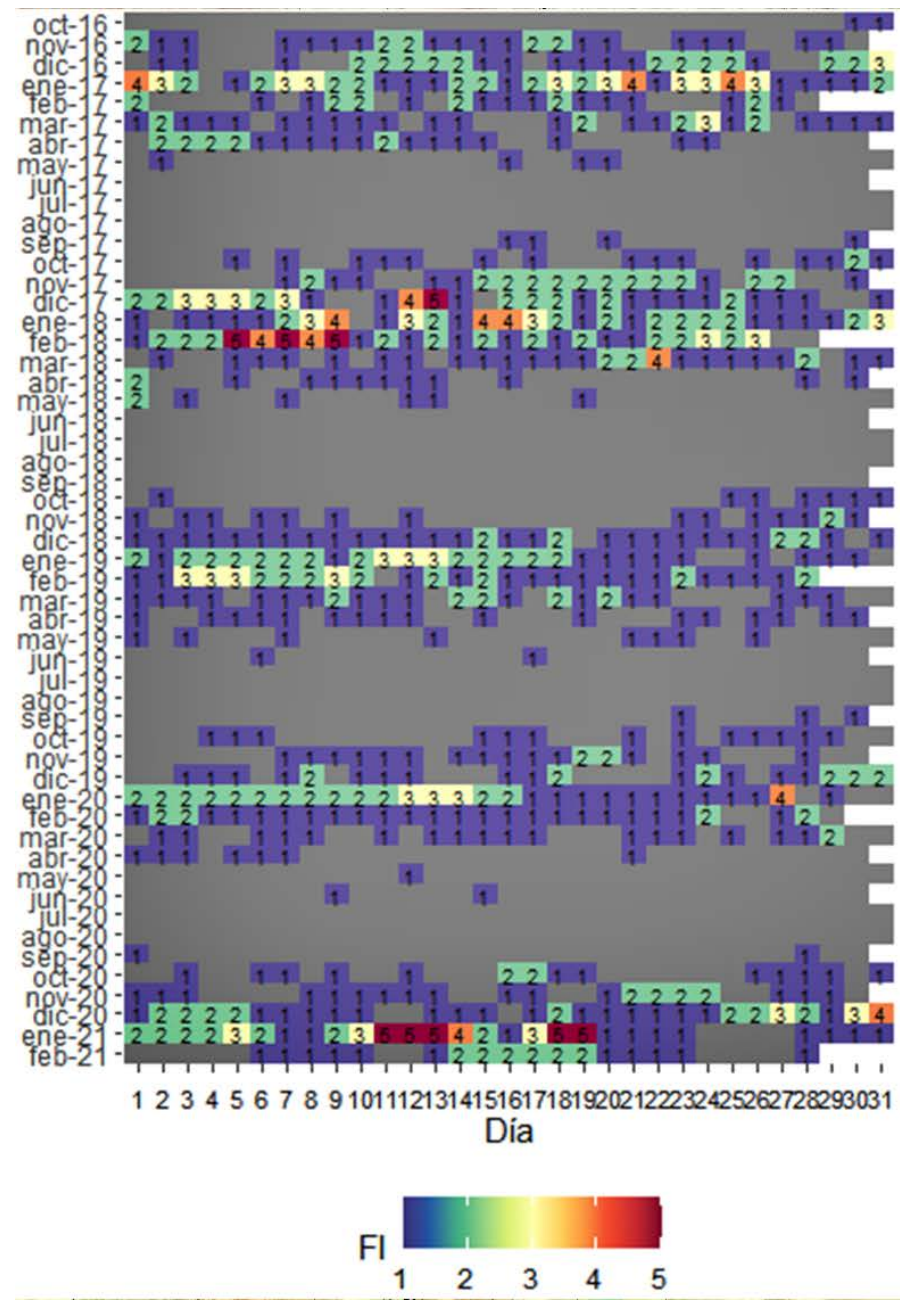

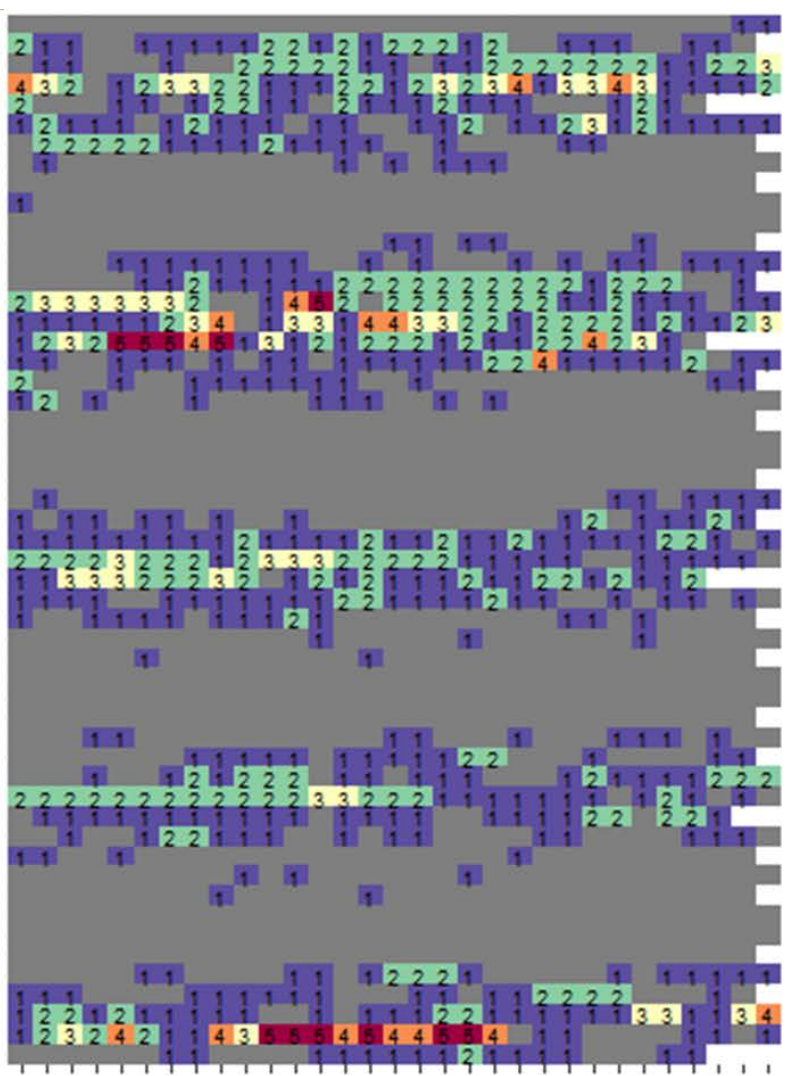

Día

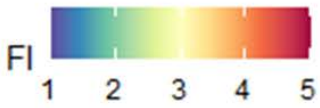

Fuente: elaboración propia

La Figura 7 muestra, a través de un mapa de calor, la distribución temporal de las temperaturas horarias en el paraje de Monterilla a lo largo de un año. Las temperaturas nocturnas más bajas tienden a expandirse en época fría y de invierno. Los valores térmicos más fríos (negativos en la mayoría de ocasiones) aparecen desde las 18.00/19.00 h de la tarde, y se extienden hasta las 8.00/9.00 h de la mañana, debido principalmente a la mayor duración de las horas nocturnas. El invierno 17/18 es el que registró las temperaturas más frías y más extensas desde el punto de vista temporal, tanto en duración como en expansión diaria (Figura 8). 
Figura 7. Calendario de la distribución de la temperatura media horaria $\left({ }^{\circ} \mathrm{C}\right)$ en Monterilla (Hernán Pelea)

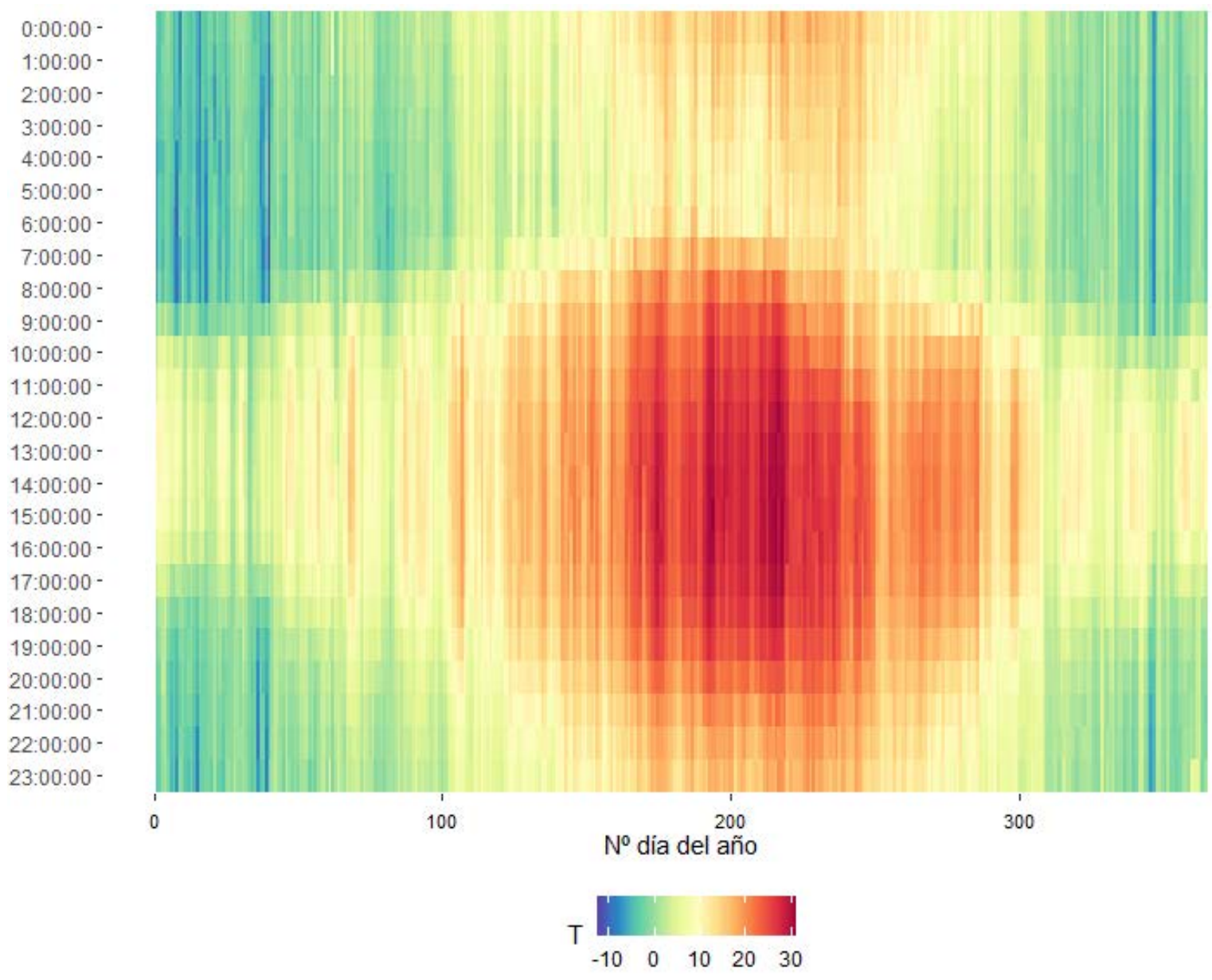

Fuente: elaboración propia

El momento más frío del año, por término medio, corresponde al 9 de febrero, a las 7:00 h de la mañana, con una temperatura media de $-12,7^{\circ} \mathrm{C}$. Por su parte, durante el verano y época más cálida, las bajas temperaturas se contraen a lo largo del día. Las temperaturas van descendiendo gradualmente durante la tarde, a diferencia de la caída más brusca de invierno. Esto es debido a la intensidad de la inversión térmica, mucho más débil en época estival. Además, se aprecia cómo, aproximadamente, a las 7.00 de la mañana, los tonos empiezan a reflejar temperaturas más suaves. 
Figura 8. Evolución térmica diezminutal $\left({ }^{\circ} \mathrm{C}\right)$

en el paraje de Monterilla-Don Fernando (15/10/2016 al 28/02/2021)

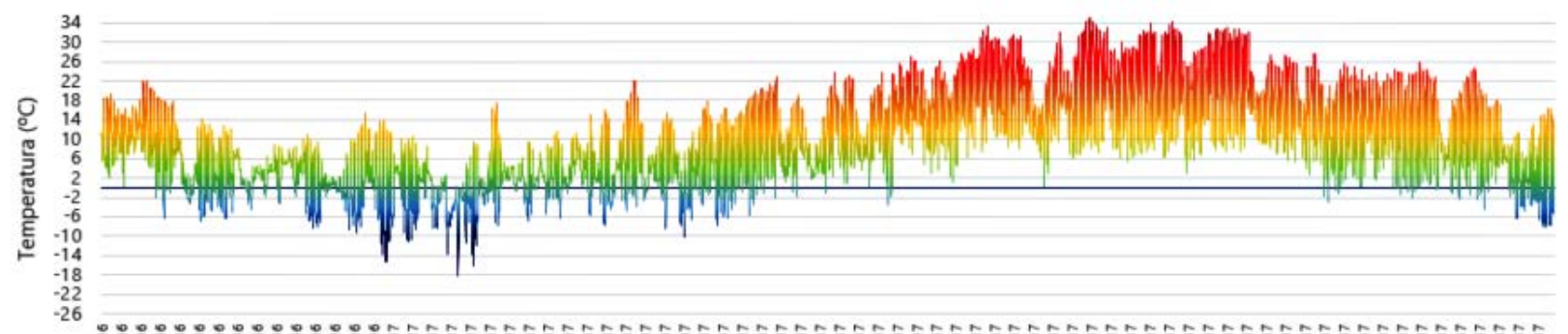

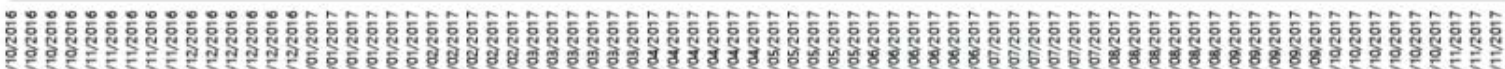
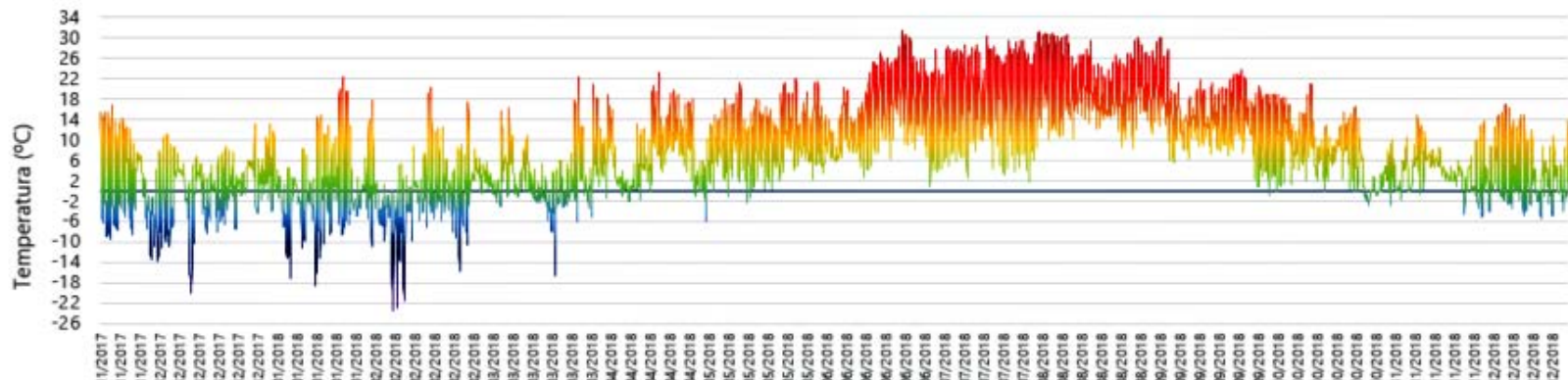

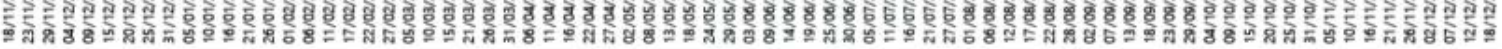
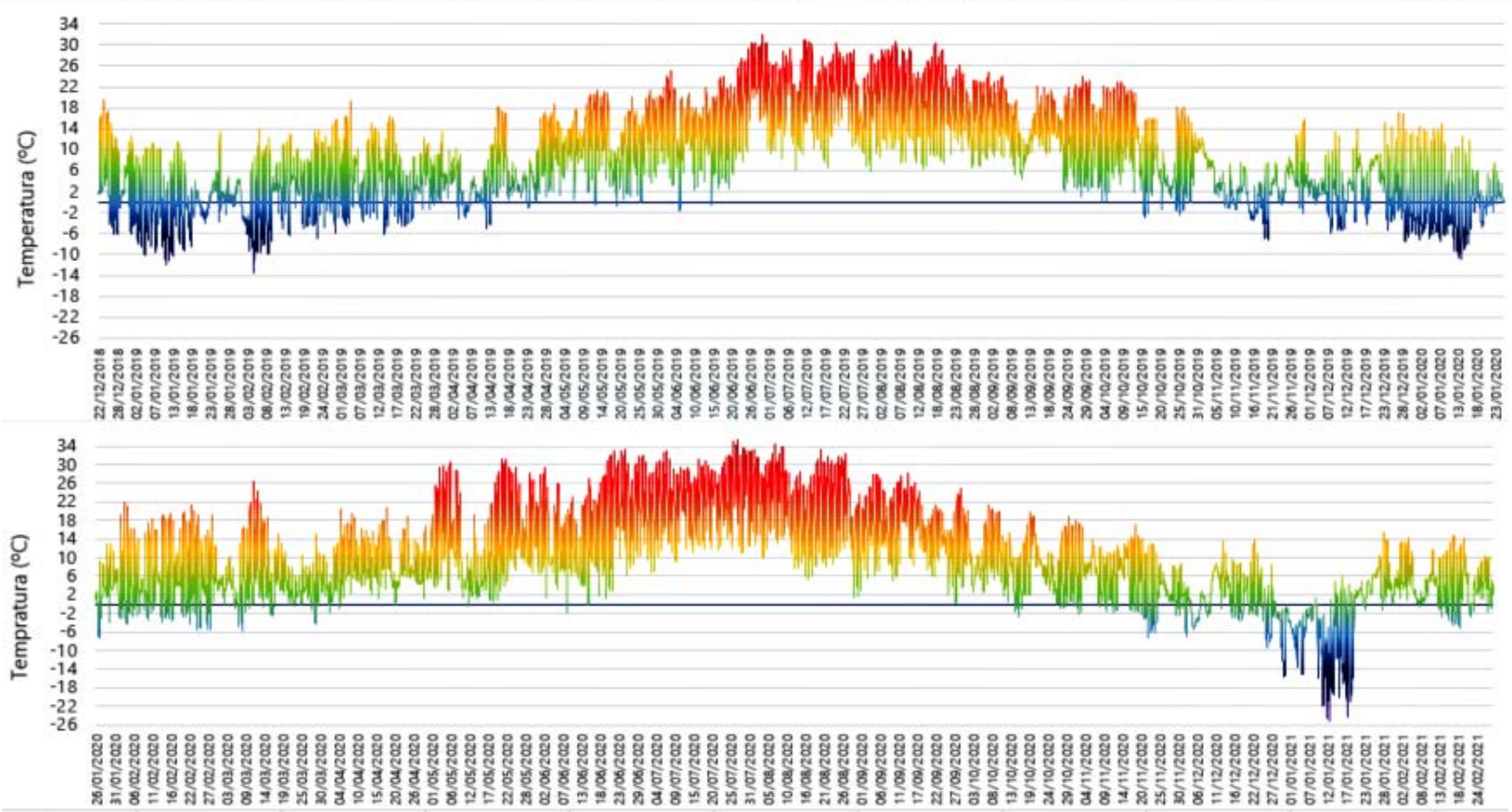

Fuente: elaboración propia

Durante los inviernos analizados se registran, por término medio, hasta 13 horas diarias con temperaturas negativas, desde media tarde (19.00 h) hasta las $8.00 \mathrm{~h}$ de la mañana. Finalmente, la alternancia de bandas diarias consecutivas con temperaturas diferentes obedece a cambios drásticos en las condiciones meteorológicas en el área de estudio (Figura 7), al analizar promedios de cinco inviernos de duración. Se alternan con mucha frecuencia advecciones atlánticas, que genera abundante nubosidad, precipitación y poca amplitud térmica, con una 
mayoría de jornadas estables, que generan importantes amplitudes térmicas diarias, con notables tasas de enfriamiento hacia la tarde-noche. Este aspecto se observa en la Figura 8, con alternancias de grandes oscilaciones térmicas diarias y periodos de varios días consecutivos donde la amplitud térmica diaria es poco significativa.

\subsection{Tipos de inversión térmica y características de las piscinas de aire frío (CAP)}

El análisis de sondeos atmosféricos nocturnos de Murcia (00 UTC) permite conocer las características de temperatura, humedad, y dirección y velocidad del viento para cada una de las altitudes de los datalogger utilizados. Además, los parámetros referentes a estabilidad atmosférica, nieve fresca en el suelo, nubosidad, presión atmosférica en superficie, o capacidad de inversión ( $\left.\mathrm{C}_{\mathbb{I N V}}\right)$ permiten identifican los principales tipos de ITN y la evolución térmica de las CAP durante las madrugadas estables.

Han sido analizados un total de 361 días de invierno (DEF), distribuidos durante los últimos cuatro periodos invernales. Se han identificado 188 jornadas con procesos de inversión térmica nocturna $(52,2 \%$ del total). Se trata de un valor relativamente bajo, aunque hay que considerar que los meses invernales en el sector más occidental de la Demarcación Hidrográfica del Segura (DHS) suelen mostrar mucha más inestabilidad que el resto de la cuenca por su clara vinculación a los tipos de tiempo atlánticos (Espín Sánchez \& Conesa García, 2018).

El tipo de CAP más común en el área de estudio corresponde a la de erosión turbulenta $(39,0 \%)$, confirmando que los inviernos en la cabecera de la DHS presentan un gran dinamismo atmosférico, incluso en periodos de estabilidad. El $2^{\circ}$ tipo predominante, con una amplia representación, es el de perturbación alta, o lo que es lo mismo, un tipo turbulento que afecta a la evolución de la temperatura en los sensores ubicados a una mayor altitud (29,1\%) (Tabla 4). La erosión turbulenta es un tipo de CAP de extracción lenta, en el que la parte superior de la piscina (datalogger a mayor altitud) se empieza a erosionar, transfiriéndose capa por capa a altitudes inferiores.

El patrón sinóptico promedio se caracteriza por una situación de dorsal subtropical, y un flujo húmedo y templado de procedencia atlántica. A pesar de que la nubosidad no es importante bajo esta situación en el Sureste de la Península, sí que suele observarse nubosidad en la Sierra de Segura (retención orográfica en niveles más elevados). Un marcado flujo en niveles medios atmosféricos (700 hPa) permite explicar la importante turbulencia en los niveles más elevados. La velocidad del viento (VV) observada en los sondeos atmosféricos nocturnos refleja una velocidad media moderada $(20 \mathrm{~km} / \mathrm{h})$ y valores homogéneos en todas las altitudes analizadas. Los valores 
disminuyen en los observatorios meteorológicos analizados, registrando $V V$ de $10,5 \mathrm{~km} / \mathrm{h}$ a 1 $200 \mathrm{~m}$ de altitud (Casas del Rey), y de solo 2,6 km/h a $430 \mathrm{~m}$ de altitud (El Chaparral). Por lo tanto, este resultado pone de manifiesto que, en zonas expuestas por encima de $900 \mathrm{~m}$ de altitud, los flujos de viento superiores a $10 \mathrm{~km} / \mathrm{h}$ erosionan la caída de la temperatura durante el proceso de ITN, aunque no lo rompen.

El flujo de viento según el sondeo atmosférico es predominantemente de componente SO en los niveles altitudinales analizados (de 208 a $229^{\circ}$ ). Esto es corroborado en los observatorios meteorológicos analizados, con direcciones medias de 211 a $183^{\circ}$ (SSO). Se trata, por tanto, de flujos de origen subtropical marítimo generados por dorsales atlánticas al oeste de la Península. Se trata de un tipo de ITN que, a pesar de sufrir erosión y una irregularidad en la evolución térmica nocturna, presenta una gran estabilidad atmosférica. Según la clasificación de Pasquill (1961), obtiene un coeficiente de 6,5 sobre 7 (estabilidad entre moderada y extrema). Se registra una altura de la capa límite de 50,2 m (52,1 promedio de todos los tipos), y un coeficiente de mezcla relativamente bajo $\left(4,6 \mathrm{~m}^{2} / \mathrm{s}\right)$ sobre una media de 10,5 en los episodios analizados. Finalmente, la nubosidad es escasa, con un promedio de 2,5 octas sobre 8, y una presión atmosférica media de 1015,4 hPa.

Esta situación atmosférica da lugar a inversiones térmicas intensas en el área de estudio. Las temperaturas mínimas se sitúan en una media de $-1,4^{\circ} \mathrm{C}\left(-2,6^{\circ} \mathrm{C}\right.$ en todos los tipos analizados), con un registro térmico, según el sondeo en el nivel geopotencial de $850 \mathrm{hPa}\left(8,8^{\circ} \mathrm{C}\right)$, que se sitúa por encima del promedio climatológico para el invierno (masa de aire templada). Se produce, además, una capacidad de inversión ( $\mathrm{C}_{\mathrm{INV}}$ ) de $-10,2^{\circ} \mathrm{C}$ (media de $-9,9^{\circ} \mathrm{C}$ ). Los datalogger analizados muestran un registro inferior a $-10^{\circ} \mathrm{C}$, con el valor más importante en Monterilla $\left(-13,1^{\circ} \mathrm{C}\right)$, y un valor mínimo en Cañada de las Yeguas $\left(-9,5^{\circ} \mathrm{C}\right)$. Para ello, es imprescindible que la tasa de enfriamiento sea importante, de ahí la caracterización de este tipo de CAP, con un fuerte descenso térmico con la puesta de sol, y posterior ralentización. Los datalogger analizados dan una tasa de enfriamiento de $-4,5^{\circ} \mathrm{C}$, en consonancia con la media de todos los episodios analizados $\left(-4,6^{\circ} \mathrm{C}\right)$. 
Tabla 4. Características de los diferentes tipos de CAP representados en el área de estudio ( 1 evolución inalterada, 2 formación tardía, 3 rotura temprana, 4 evento de mezcla, 5 perturbación alta, 6 perturbación baja, 7 erosión turbulenta y 8 ventana de inversión).

\begin{tabular}{|c|c|c|c|c|c|c|c|c|}
\hline Tipo CAP & 1 & 2 & 3 & 4 & 5 & 6 & 7 & 8 \\
\hline $\mathrm{N}^{\circ}$ eventos & 27 & 20 & 1 & 9 & 55 & 0 & 73 & 3 \\
\hline$\%$ Eventos & 14,2 & 10,6 & 0,7 & 5,0 & 29,1 & 0,0 & 39,0 & 1,4 \\
\hline $\mathrm{C}_{\mathrm{INV}}\left({ }^{\circ} \mathrm{C}\right)$ & 11,3 & 8,6 & 12,5 & 7,6 & 10,7 & * & 10,2 & 8,1 \\
\hline $\mathrm{TE}\left({ }^{\circ} \mathrm{C}\right)$ & 5,5 & 4,6 & 7,4 & 2,9 & 5,9 & * & 4,5 & 1,7 \\
\hline $\mathrm{TNm}\left({ }^{\circ} \mathrm{C}\right)$ & $-2,6$ & $-2,4$ & $-5,5$ & $-0,1$ & $-1,7$ & * & $-1,4$ & $-5,2$ \\
\hline DV sondeo $\left({ }^{\circ}\right)$ & 245,8 & 230,8 & 306,7 & 134,4 & 208,8 & * & 214,9 & 279,4 \\
\hline$V V$ sondeo $(\mathrm{km} / \mathrm{h})$ & 16,1 & $27, .5$ & 31,6 & 24,5 & 18,6 & * & 20,9 & 27,8 \\
\hline HR sondeo (\%) & 49,6 & 58,7 & 20,7 & 58,7 & 46,7 & * & 48,5 & 79,3 \\
\hline Coef. Pasquill & 6,6 & 6,0 & 7,0 & 6,3 & 6,5 & * & 6,5 & 6,0 \\
\hline $\mathrm{Zi}(\mathrm{m})$ & 50,0 & 53,8 & 50,0 & 60,3 & 50,4 & * & 50,2 & 50,0 \\
\hline $\mathrm{Kz}\left(\mathrm{m} / \mathrm{s}^{2}\right)$ & 2,6 & 15,5 & 0,3 & 17,9 & 9,7 & * & 4,6 & 22,6 \\
\hline $\mathrm{PA}(\mathrm{hPa})$ & 1014,6 & 1015,2 & 1001,2 & 1014,9 & 1015,5 & * & 1015,4 & 1007,3 \\
\hline Nubosidad (octas) & 1,9 & 2,6 & 3,2 & 3,5 & 2,0 & * & 2,5 & 0,0 \\
\hline Inicio CAP (h) & 18.43 & 3.00 & 20.02 & 23.06 & 19.01 & * & 22.06 & 2.06 \\
\hline Destrucción CAP (h) & 10.09 & 10.03 & 2.57 & 10.05 & 10.12 & * & 10.05 & 5.05 \\
\hline Duración (h.) & 16,1 & 7,0 & 7,0 & 11,0 & 15,7 & * & 12,0 & 3,0 \\
\hline
\end{tabular}

Fuente: elaboración propia

La constitución de la CAP de erosión turbulenta se produce por término medio a las 22.06 h. Se trata de una hora relativamente tardía, en comparación especialmente con la evolución inalterada (18.43 h). Ello repercute en que la tasa de enfriamiento durante primeras horas de la tarde no sea tan elevada como en otros tipos de $\operatorname{CAP}\left(4,5^{\circ} \mathrm{C}\right)$, aunque se mantiene en la media de todas las jornadas analizadas $\left(4,6^{\circ} \mathrm{C}\right)$. Finalmente, la rotura del estrato de inversión térmica tiene lugar a las $10.05 \mathrm{~h}$, un valor similar a la del resto de tipologías. 
En definitiva, el tipo de CAP de erosión turbulenta, se caracteriza por unos procesos intensos de inversión térmica, si bien no alcanza los valores del tipo de evolución inalterada. El flujo de viento en niveles medios atmosféricos, algo más importante, provoca erosión y alteración en la evolución de la temperatura en zonas de inversión térmica durante las horas nocturnas.

Entre ambos tipos representan el 68,1\% de las CAP durante el trimestre invernal. Además, es preciso considerar que el tipo de CAP que presenta mayor estabilidad, el de la evolución inalterada, no adquiere una gran representación en el área de estudio, si bien su representación porcentual se sitúa en el 14,2 \%. Finalmente, el tipo de CAP de perturbación baja no es identificado en el área de estudio, y otros tipos, como el de ventana de inversión o la rotura temprana de la ITN, apenas tienen relevancia (Tabla 4).

Desde el punto vista mensual, diciembre, debido principalmente a su mayor condición anticiclónica, representa el $55 \%$ de las CAP registradas, mientras que enero y febrero (43\%) presentan menos eventos de ITN. A pesar de que aparecen representados 7 de los 8 tipos de CAP en el área de estudio, solo tres llegan a representar el 82,3\% del total. La Tabla 4 muestra los resultados promedio de las variables analizadas para cada tipo.

Las 188 jornadas identificadas con proceso de ITN revelan algunos datos de interés. Las horas nocturnas se caracterizan, según los datos arrojados por el sondeo atmosférico, por bajos valores higrométricos $(51,4 \%)$, y una velocidad media del viento moderada $(23,8 \mathrm{~km} / \mathrm{h})$ de componente suroeste. Además, la nubosidad es relativamente escasa (2,5 octas), una presión atmosférica superficial relativamente baja $(1012,0 \mathrm{hPa})$, y unos elevados parámetros de estabilidad según Pasquill (6,4 sobre 7). Todo ello con una altura de la capa límite extremadamente baja $(52,1 \mathrm{~m})$, y un coeficiente de mezcla vertical débil, de $10,5 \mathrm{~m} / \mathrm{s}^{2}$, que garantiza intensos procesos de estabilidad nocturna.

La humedad relativa en niveles bajos-medios atmosféricos es de vital importancia para generar intensos procesos de ITN. A menor humedad relativa, la capacidad de inversión aumenta (coeficiente de correlación del 0,68). Los valores de CINV entre muy fuertes y excepcionalmente fuertes $\left(>12^{\circ} \mathrm{C}\right)$ tienen lugar con valores higrométricos entre 20 y $40 \%$ (Figura 9). El coeficiente de mezcla vertical $(K z)$ es uno de los factores que más peso tiene en la intensidad de los procesos de ITN. Ocurre igual en el actual análisis, donde los valores de Kz muestran una importante relación con los valores de capacidad de inversión ( $\left.\mathrm{Cl}_{\mathrm{NV}}\right)$. Las madrugadas (0-6 h) con escasa o nula turbulencia/mezcla vertical suelen generar las diferencias de temperaturas más importantes durante las noches de inversión térmica. Por ejemplo, con valores inferiores de 
$\mathrm{Kz}$ de 0,88 $\mathrm{m}^{2} / \mathrm{s}$, las temperaturas son más bajas en Monterilla y Nava de los Troncos, con diferencias medias de 5,0 a $5,2^{\circ} \mathrm{C}$ con Navalasno. Sin embargo, conforme aumenta el coeficiente de mezcla vertical, las diferencias, dentro de madrugadas estables, tienden a igualarse. Del mismo modo, los valores medios de $\mathrm{C}_{\mathbb{I N V}}$ superan los $10^{\circ} \mathrm{C}$ solamente con valores de $\mathrm{Kz}$ inferiores a $0,88 \mathrm{~m}^{2} / \mathrm{s}$ (Tabla 4$)$.

Figura 9. Cartografía sinóptica promedio del tipo de CAP de erosión turbulenta: a) presión atmosférica superficial ( $\mathrm{hPa}$; ; b) humedad relativa (\%) en el geop.de $850 \mathrm{hPa}$; c) viento en el geop. de $700 \mathrm{hPa}$; y del tipo perturbación alta; d) presión atmosférica superficial; e) humedad relativa (\%) en el geop. de $850 \mathrm{hPa}$; f) viento en el geop. de $700 \mathrm{hPa}$
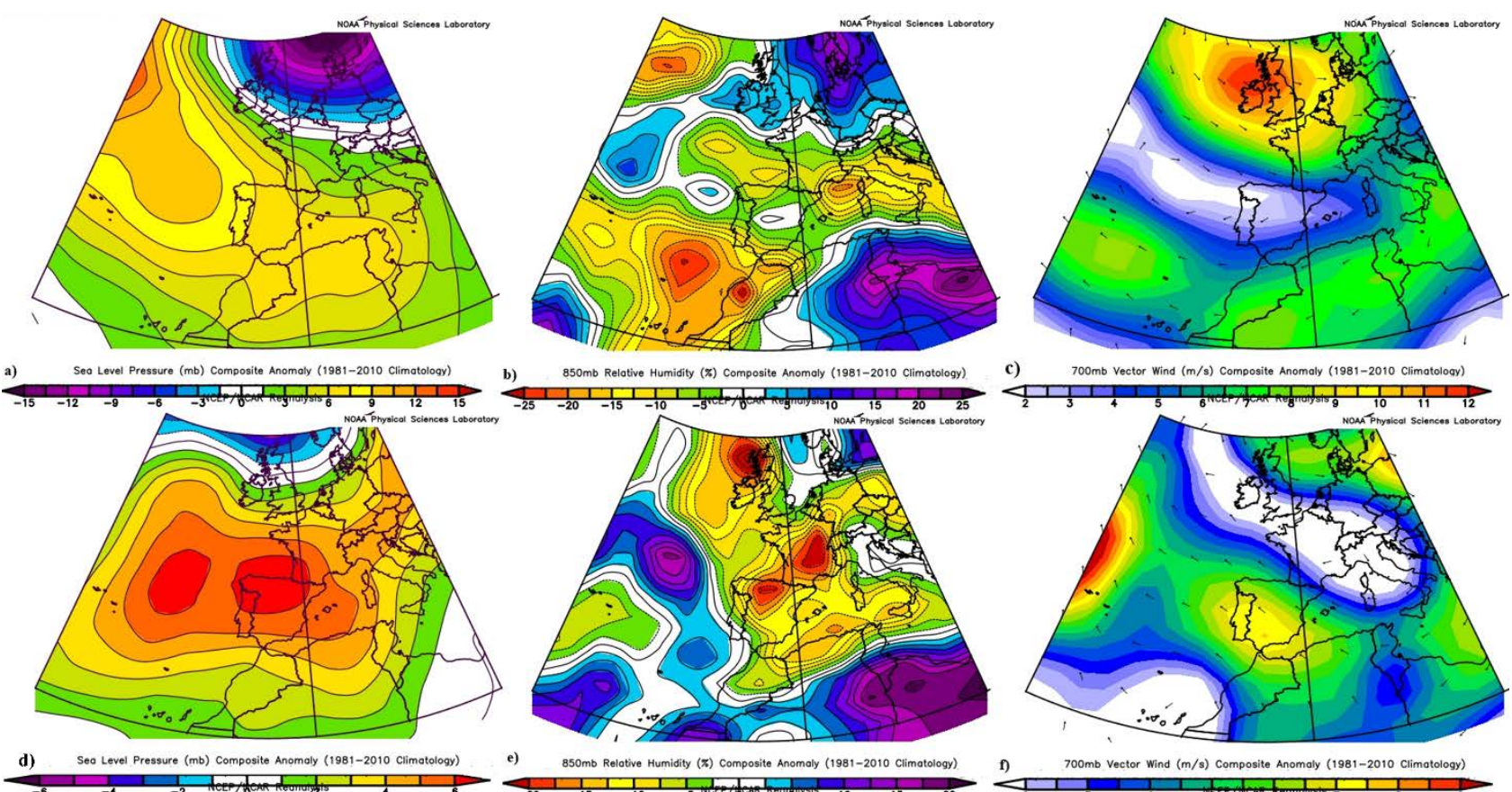

850mb Relotive Humidity $(x)$ Composite Anomaly (1981-2010 Climatology)

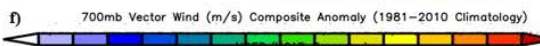

Fuente: elaboración propia a partir de NOAA

\subsection{Factores sinópticos y de microescala asociados a temperaturas mínimas extremas $\left(<-15^{\circ} \mathrm{C}\right)$}

Durante el periodo de análisis han sido analizados cinco trimestres invernales, que no contienen olas de frío recientes e históricas, como las de enero de 2005 o febrero de 2012. Aun así, el área de estudio ha llegado a registrar temperaturas mínimas extremadamente frías en multitud de ocasiones durante los cinco inviernos. En concreto, un total de 29 jornadas tuvieron temperaturas mínimas igual o inferiores a $-15^{\circ} \mathrm{C}$ (11 de ellos inferior a $-20^{\circ}-\mathrm{C}$ ). A continuación, se analizan los factores desencadenantes desde el punto de vista sinóptico y de microescala. 
- La configuración sinóptica en el nivel geopotencial de 500 hPa muestra una vaguada polar continental de onda corta, cuyo eje NE-SO afecta principalmente al sureste de la Península Ibérica, con anomalías de 100 m respecto al modelo climatológico 1981-2010. Ello da como resultado la presencia de una masa de aire frío en niveles medios-altos atmosféricos con una anomalía de temperatura de entre $-2 /-3^{\circ} \mathrm{C}$, respecto a lo habitual en periodo invernal. Se aprecia una advección fría procedente de Europa oriental-Siberia. Por su parte, las anomalías positivas en los geopotenciales de 500 y 850 hPa se sitúan al oeste de las Islas Británicas y en sector centro-septentrional del continente africano, configurando un marcado pasillo frío sobre el continente europeo (Figura 10b y $10 \mathrm{~d}$ ).

- A nivel superficial se produce un marcado pantano barométrico sobre la Península lbérica (con anomalías neutras respecto al promedio climatológico invernal). En general, aparecen altas presiones muy marcadas al oeste de las Islas Británicas, y bajas presiones relativas en el sector meridional del continente europeo. Como consecuencia, se genera un pasillo de vientos de componente norte-noroeste (N-NE), con mayor velocidad en la mitad oeste peninsular, y un viento, en general bastante débil, sobre el área de estudio (Figura 10c y 10e).

- El predominio de vientos de componente NE en niveles medios-altos atmosféricos genera una masa de aire seca, con poca carga higrométrica (anomalía de -5/-10\%). Ello da lugar a un punto de rocío extremadamente bajo, lo que, unido a las importantes anomalías térmicas superficiales $\left(-4 /-5^{\circ} \mathrm{C}\right)$, refuerza los descensos térmicos nocturnos más notables.

- El paso de una zona de inestabilidad (frente) sobre el área de estudio, asociada al sector delantero de la vaguada, genera copiosas precipitaciones en forma de nieve potenciadas por el efecto orográfico del arco bético, clave para los desplomes súbitos de temperaturas y sobreenfriamiento durante los procesos de inversión térmica nocturna en horas posteriores. La superficie nivosa aparece en las 29 jornadas analizadas con valores inferiores a $-15^{\circ} \mathrm{C}$. La nieve proporciona una capa aislante que limita el flujo de calor del suelo hacia arriba, que normalmente contrarrestaría las pérdidas de radiación de onda larga desde la superficie (Whiteman et al., 2004). En el área de estudio, el espesor de nieve fresca influye en que las temperaturas mínimas son más bajas en el paraje de Monterilla ( $R^{2}$ de -0,53) (Figura 12a). Todas las temperaturas mínimas iguales o inferiores a $-15^{\circ} \mathrm{C}$ se acompañan de nieve en la superficie $\left(10,5 \mathrm{~kg} / \mathrm{m}^{2}\right)$. 
Figura 10. Cartografía sinóptica promedio de las jornadas de ITN con las temperaturas mínimas más bajas: a) humedad relativa (\%) en el nivel geopotencial de $300 \mathrm{hPa}$;

b) altura geopotencial en $500 \mathrm{hPa}$; c) dirección y velocidad del viento en el geopotencial de $700 \mathrm{hPa}$; d) temperatura del aire $\left({ }^{\circ} \mathrm{C}\right)$ en el geopotencial de $850 \mathrm{hPa}$;

e) presión atmosférica al nivel del mar $(\mathrm{hPa})$; f) anomalía térmica superficial a $2 \mathrm{~m}\left({ }^{\circ} \mathrm{C}\right)$
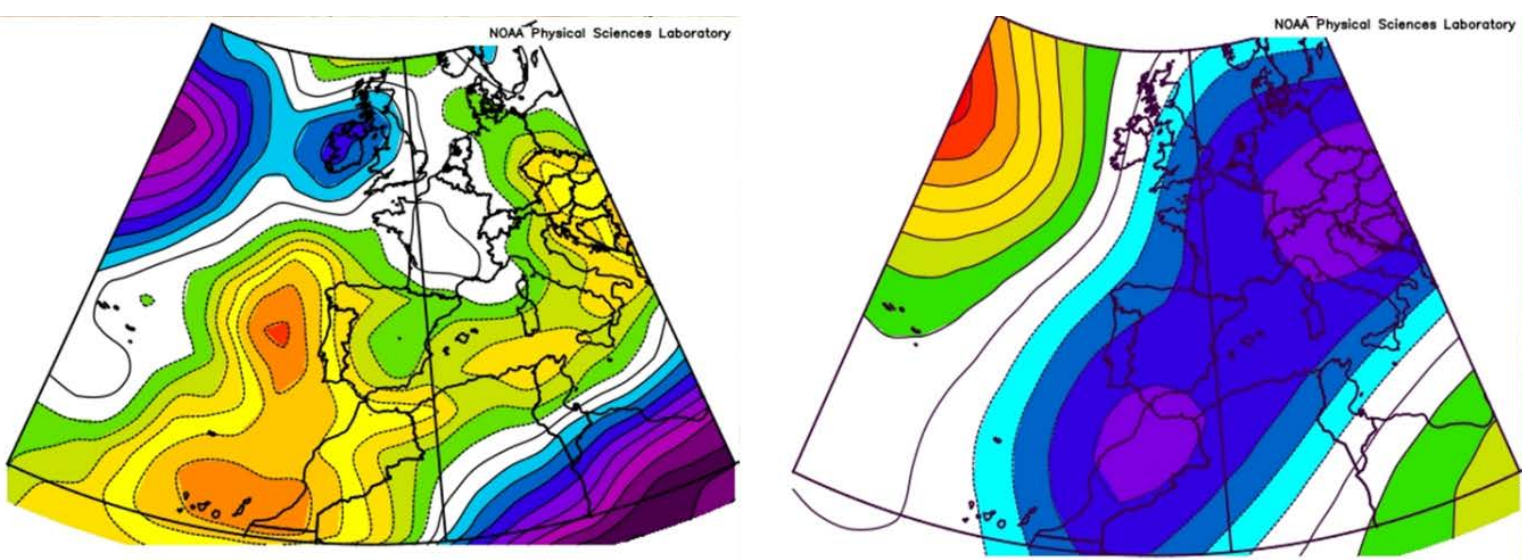

a)

$300 \mathrm{mb}$ Relotive Humidity (\%) Composite Anomaly (1981-2010 Climatology)

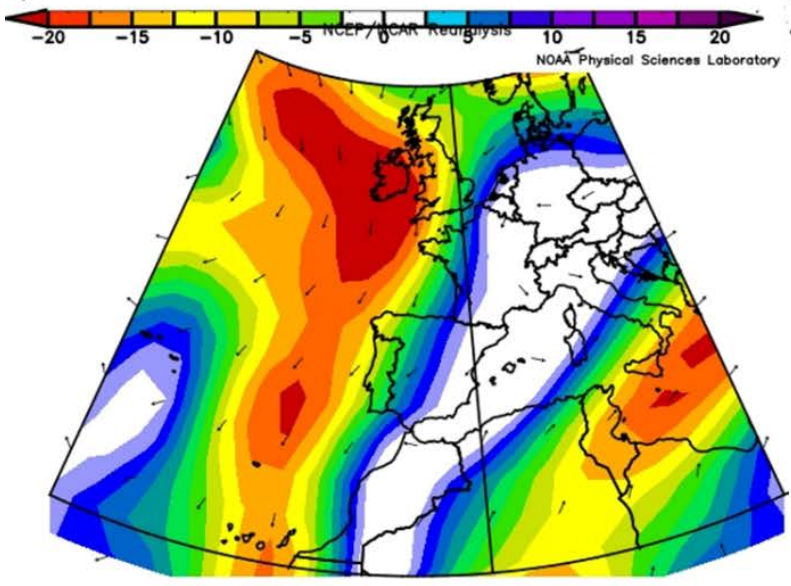

c)

$700 \mathrm{mb}$ Vector Wind (m/s) Composite Anomaly (1981-2010 Climatology)

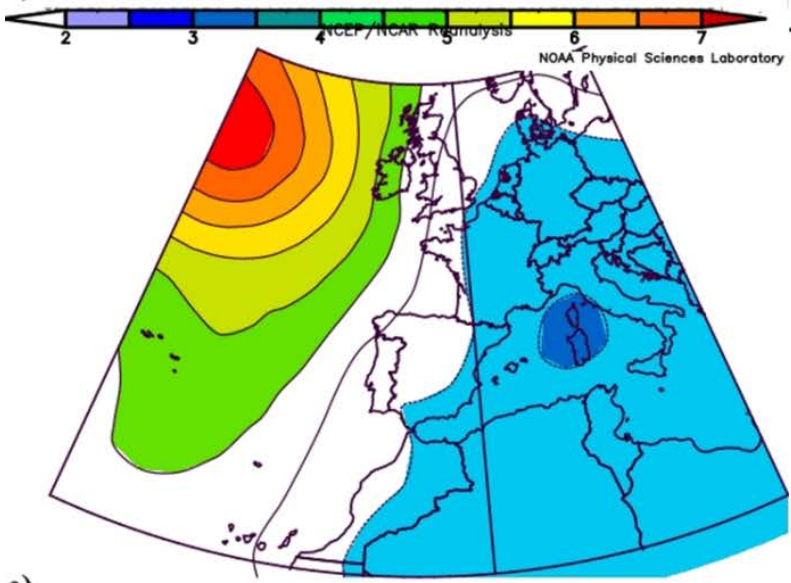

d)

b) 500mb Geopotential Heiaht (m) Composite Anomaly (1981-2010 Climatoloav)

e)

Sea Level Pressure (mb) Composite Anomaly (1981-2010 Climatology)

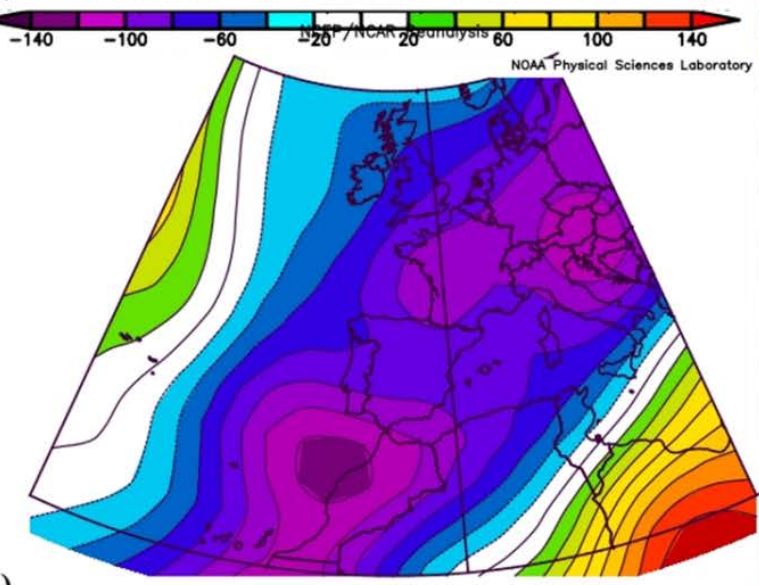

d) $850 \mathrm{mb}$ Air Temperature (K) Composite Anomoly (1981-2010 Climatology)

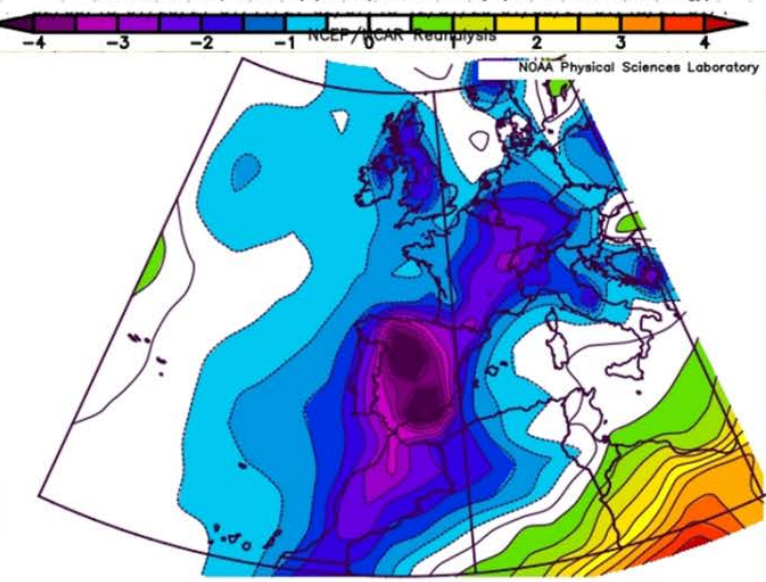

f)

$2 m$ Composite Anomaly (1981-2010 Climatology)
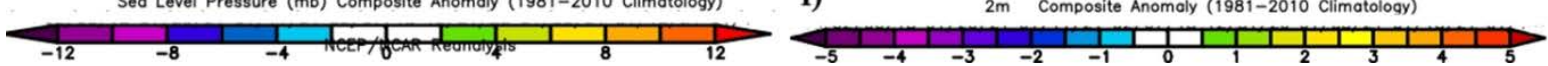

Fuente: elaboración propia a partir de NOAA 
Tabla 5. Características del perfil atmosférico promedio arrojado

por sondeos nocturnos de la ciudad de Murcia (00 h UTC)

en las 29 jornadas con temperaturas mínimas inferiores a $-15^{\circ} \mathrm{C}$

\begin{tabular}{|l|c|c|c|c|c|}
\hline $\begin{array}{c}\text { Variable / nivel } \\
\text { geopotencial }\end{array}$ & $1000 \mathrm{hPa}$ & $850 \mathrm{hPa}$ & $700 \mathrm{hPa}$ & $500 \mathrm{hPa}$ & $300 \mathrm{hPa}$ \\
\hline Altitud geopotencial (m) & 180,3 & 1491,4 & 3024,3 & 5560,2 & 9102,6 \\
\hline Temperatura $\left({ }^{\circ} \mathrm{C}\right)$ & 8,3 & 1,9 & $-6,3$ & $-23,0$ & $-47,7$ \\
\hline Punto de rocío $\left({ }^{\circ} \mathrm{C}\right)$ & $-0,7$ & $-7,3$ & $-21,1$ & $-37,7$ & $-61,4$ \\
\hline Humedad relativa (\%) & 55,6 & 55,7 & 38,6 & 35,8 & 22,9 \\
\hline Dirección del viento & $\mathrm{NO}$ & $\mathrm{N}$ & $\mathrm{NE}$ & $\mathrm{NE}$ & $\mathrm{N}$ \\
\hline Velocidad del viento $(\mathrm{km} / \mathrm{h})$ & 15,4 & 21,8 & 27,0 & 56,6 & 80,5 \\
\hline
\end{tabular}

Fuente: elaboración propia a través de datos obtenidos

de sondeos atmosféricos nocturnos de la ciudad de Murcia

Los sondeos aerológicos nocturnos registrados en las jornadas de análisis muestran un perfil atmosférico caracterizado por una masa de aire con poca carga higrométrica. Los valores fluctúan desde el $56 \%$ en capas superficiales $(1000 \mathrm{hPa})$ hasta valores inferiores al $23 \%$ en el nivel geopotencial de $300 \mathrm{hPa}$, lo que contribuye a que los procesos de inversión térmica sean más intensos (Tabla 5). Por su parte, los datos arrojan la presencia de una masa de aire frío, pero sin valores extraordinarios. En el nivel geopotencial de $850 \mathrm{hPa}$ la temperatura es de $1.9^{\circ} \mathrm{C}$, por lo que no es un requisito imprescindible que la advección fría registre temperaturas excesivamente bajas $\left(-23,0^{\circ} \mathrm{C}\right.$ a $\left.500 \mathrm{hPa}\right)$ (Figura 11).

En general, las alturas geopotenciales en los diferentes niveles analizados muestran valores promedio acordes a la media climatológica invernal. Se trata de situaciones donde la velocidad del viento sinóptico en niveles medios-bajos atmosféricos es relativamente pequeña, inferior a 30 $\mathrm{km} / \mathrm{h}$ en los primeros $3000 \mathrm{~m}$ de columna atmosférica.

La capacidad de inversión ( $\mathrm{C}_{\mathbb{N}}$ ) durante las jornadas analizadas es muy notable, con un promedio de $20,5^{\circ} \mathrm{C}$. Durante las 29 jornadas, la temperatura media de las mínimas registradas en los datalogger del área de estudio fue de $-19,5^{\circ} \mathrm{C}$, mientras que la temperatura geopotencial a $1660 \mathrm{~m}\left(830 \mathrm{hPa}\right.$ ) fue de $1,0^{\circ} \mathrm{C}$. Por tanto, la diferencia de más de $20^{\circ} \mathrm{C}$ arroja unos procesos de inversión térmica realmente intensos. 
Figura 11. Sondeo atmosférico nocturno promedio de la ciudad de Murcia (00 h UTC) en las 29 jornadas con temperaturas mínimas inferiores a $-15^{\circ} \mathrm{C}$. $\mathrm{T}$ es la temperatura del aire $\left({ }^{\circ} \mathrm{C}\right)$ y $\mathrm{Td}$ es el punto de rocío $\left({ }^{\circ} \mathrm{C}\right)$, representados en el eje de la izquierda, y $\mathrm{V} V$ es la velocidad del viento $(\mathrm{km} / \mathrm{h})$, representada en el eje de la derecha

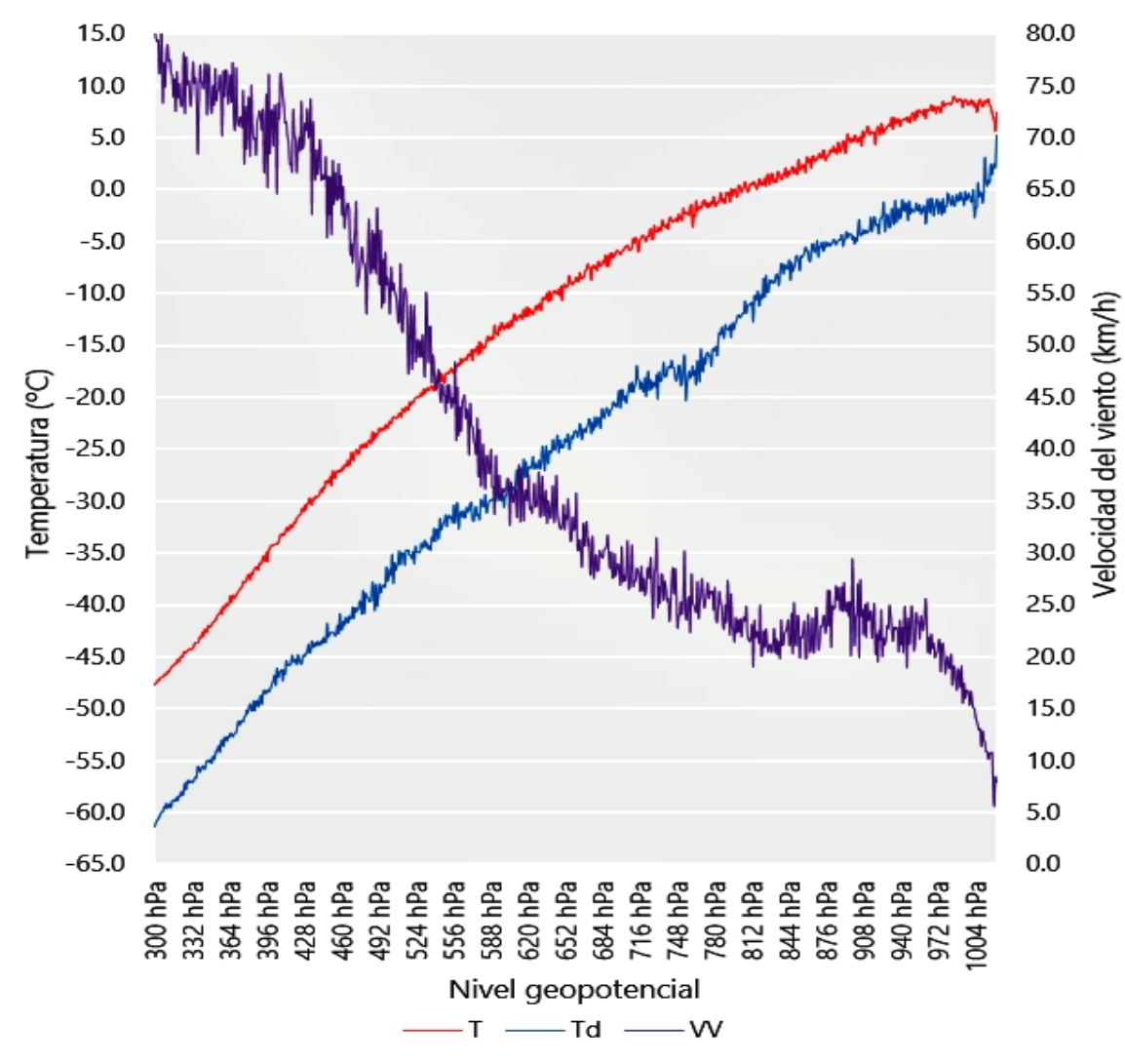

Fuente: elaboración propia a partir de meteociel.fr

Finalmente, durante las jornadas de análisis fueron calculados la altura de la capa límite (Zi) y el coeficiente de mezcla vertical (Kz), dos variables para medir la estabilidad en los primeros metros de la atmósfera durante las horas nocturnas. En general, el promedio de la altura de la capa límite durante las horas nocturnas (0-6 horas) es de 65,3 metros, un valor bajo, caracterizando una capa límite muy delgada. La mayoría de jornadas analizadas registran una altura inferior a $55 \mathrm{~m}$, si bien en algunas jornadas se registran valores de entre 60 y 190 metros. Por su parte, el coeficiente de mezcla vertical arroja un promedio de $23,9 \mathrm{~m}^{2} / \mathrm{s}$, lo que puede calificarse como una agitación mínima. Este valor es extraordinariamente bajo $\left(<1 \mathrm{~m}^{2} / \mathrm{s}\right)$ durante algunas jornadas analizadas ( 1 de enero de 2017, 9 de enero 2018 y las jornadas del 18 y 19 de enero de 2021), lo que dio lugar a inversiones térmicas extraordinariamente intensas en el área de estudio. 
Figura 12. Correlación estadística según Spearman entre a) temperaturas mínimas registradas vs. acumulación de nieve fresca;

b) humedad relativa vs. capacidad de inversión térmica ( $\left.\mathrm{C}_{\mathrm{INV}}\right)$

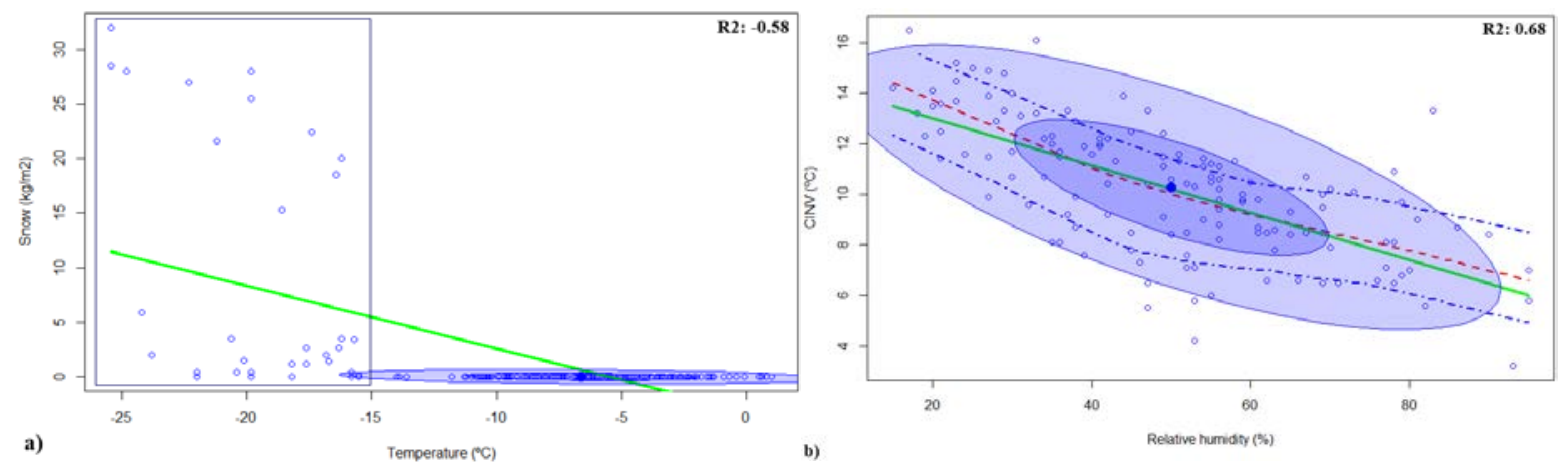

Fuente: elaboración propia

\subsection{Episodio frío del 11-19 de enero de 2021}

El inicio del mes de enero de 2021 estuvo marcado por la irrupción de una potente advección fría unida a importantes nevadas generadas por la borrasca Filomena, que contribuyó notablemente al registro de temperaturas mínimas extraordinariamente bajas en el centro de la Península Ibérica.

Figura 13. Configuración sinóptica del 11 de enero de 2021 a las 12 h UTC

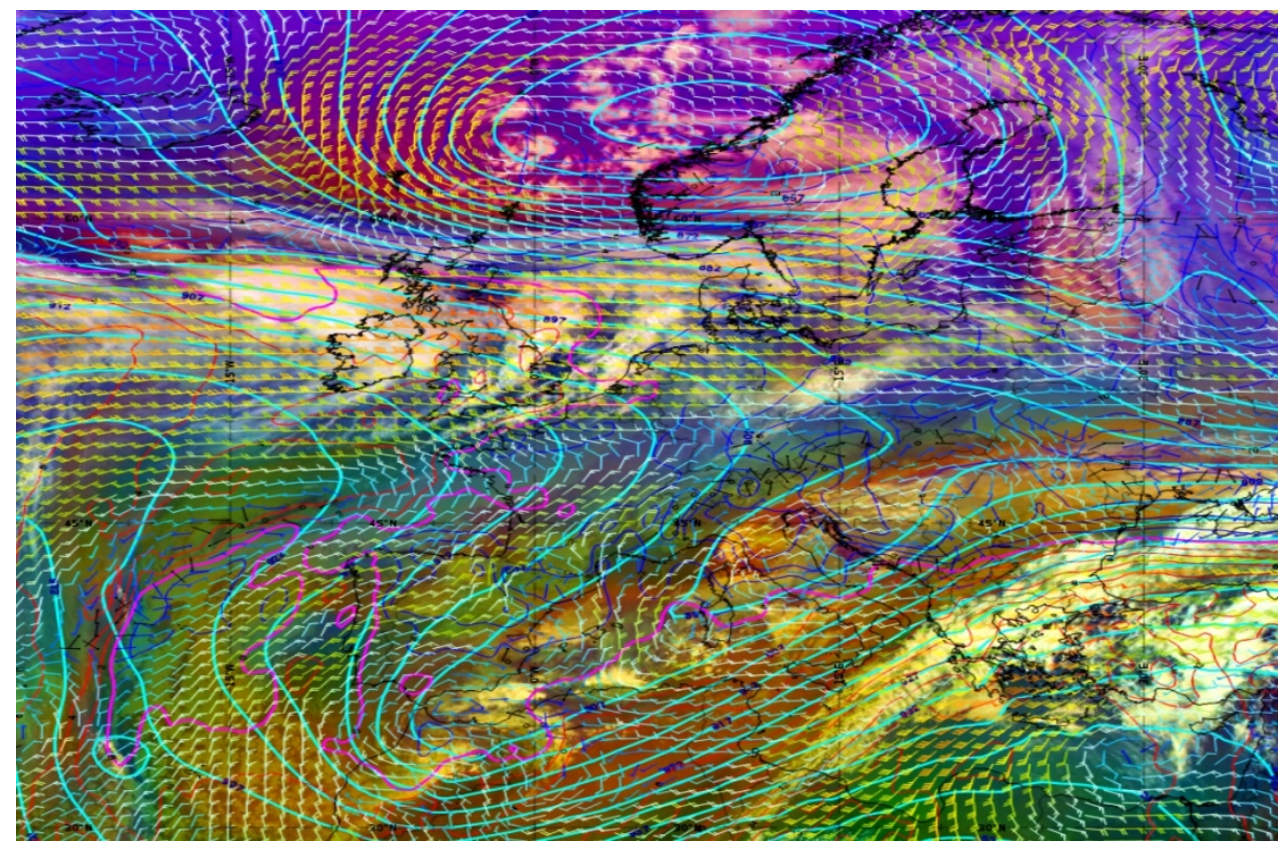

Leyenda: Líneas azules: altura geopotencial a $300 \mathrm{hPa}$; líneas rosas: temperatura a $850 \mathrm{hPa}$; y fondo: canal masas de aire de EUMETSAT.

Fuente: eumetrain.org 
La borrasca Filomena se genera en el interior este de EE. UU el día 1 de enero, y se desplaza hacia Terranova (Canadá) (2 de enero), siguiendo luego hacia latitudes medias del océano Atlántico. Posteriormente se situó al norte de las islas Canarias (7 de enero), donde entra en contacto con aguas más cálidas y se refuerza, adquiriendo características próximas a las de los ciclones tropicales. La borrasca Filomena es nombrada así por AEMET el día 5 de enero (Agencia Estatal de Meteorología, 2021), y accede a la Península lbérica a través del estrecho de Gibraltar, con un desplazamiento sur-norte, hacia regiones más septentrionales (Figura 13). En su camino, con características de borrasca extratropical, interactúa con la llegada de una masa de aire frío impulsada por una cuña anticiclónica al oeste de Irlanda, y bajas presiones sobre el mar Mediterráneo central. Sobre la Península se genera un pasillo de vientos de componente noreste que ayuda a canalizar el aire frío.

Figura 14. Retrotrayectorias de las masas de aire a 5500, 1500 y 500 m de altitud, desde el 6 al 11 de enero de 2021

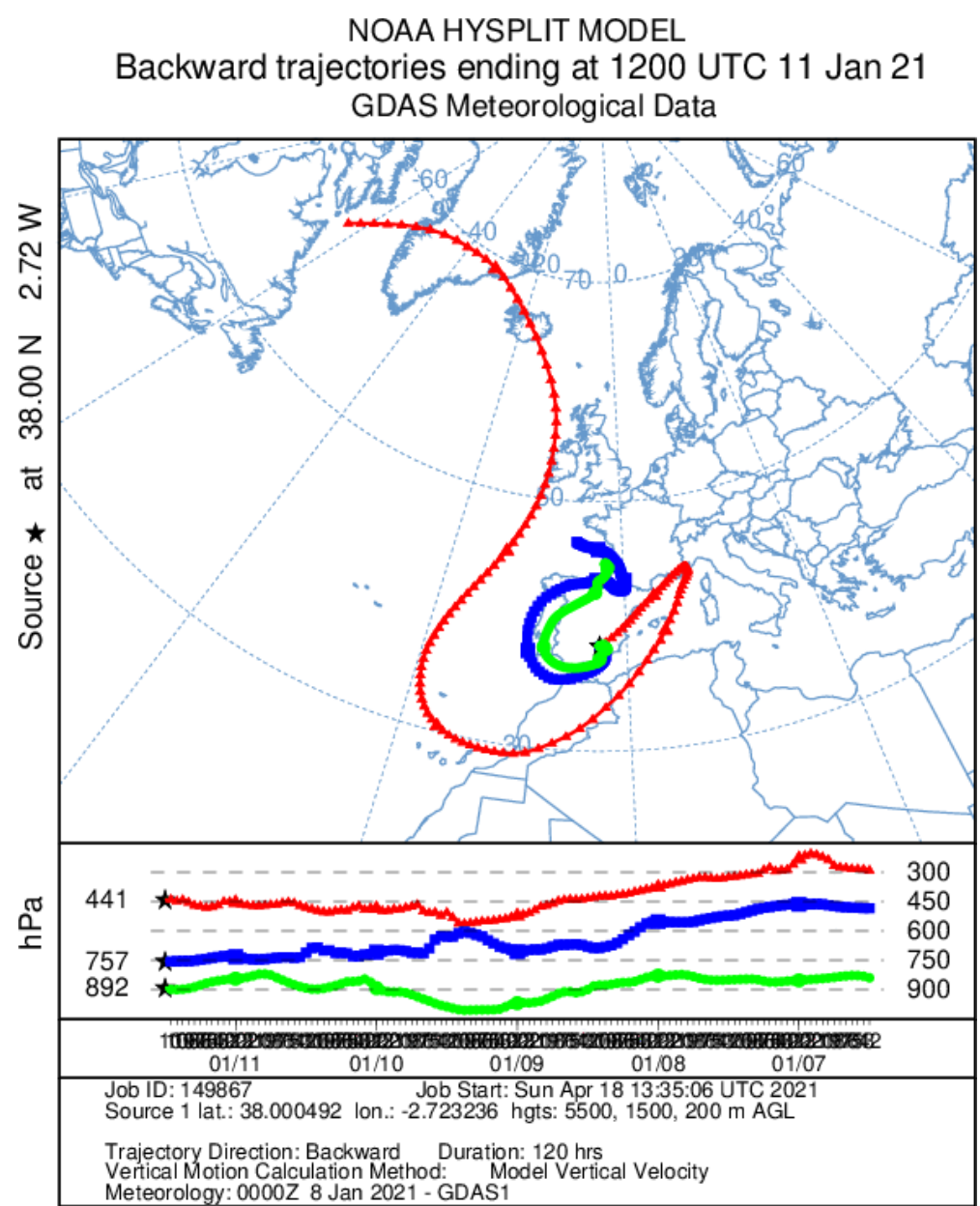

Fuente: noaa.gov 
A partir del 7 de enero la borrasca Filomena se posiciona sobre el golfo de Cádiz, con una baja secundaria a sotavento de Argelia. El flujo cálido y húmedo de origen subtropical que se genera en su parte delantera produce intensas precipitaciones en forma de nieve sobre el área de estudio. Se registran espesores de 30 a $50 \mathrm{~cm}$ en zonas habitadas de la Sierra de Segura, prolongándose hasta el 10 de enero, con una estimación de 28,5 kg/m² (Snow Mass 9 km de MODIS).

Figura 15. Sondeo termodinámico lanzado

el 12 de enero de 2021 a las 00 UTC desde Murcia

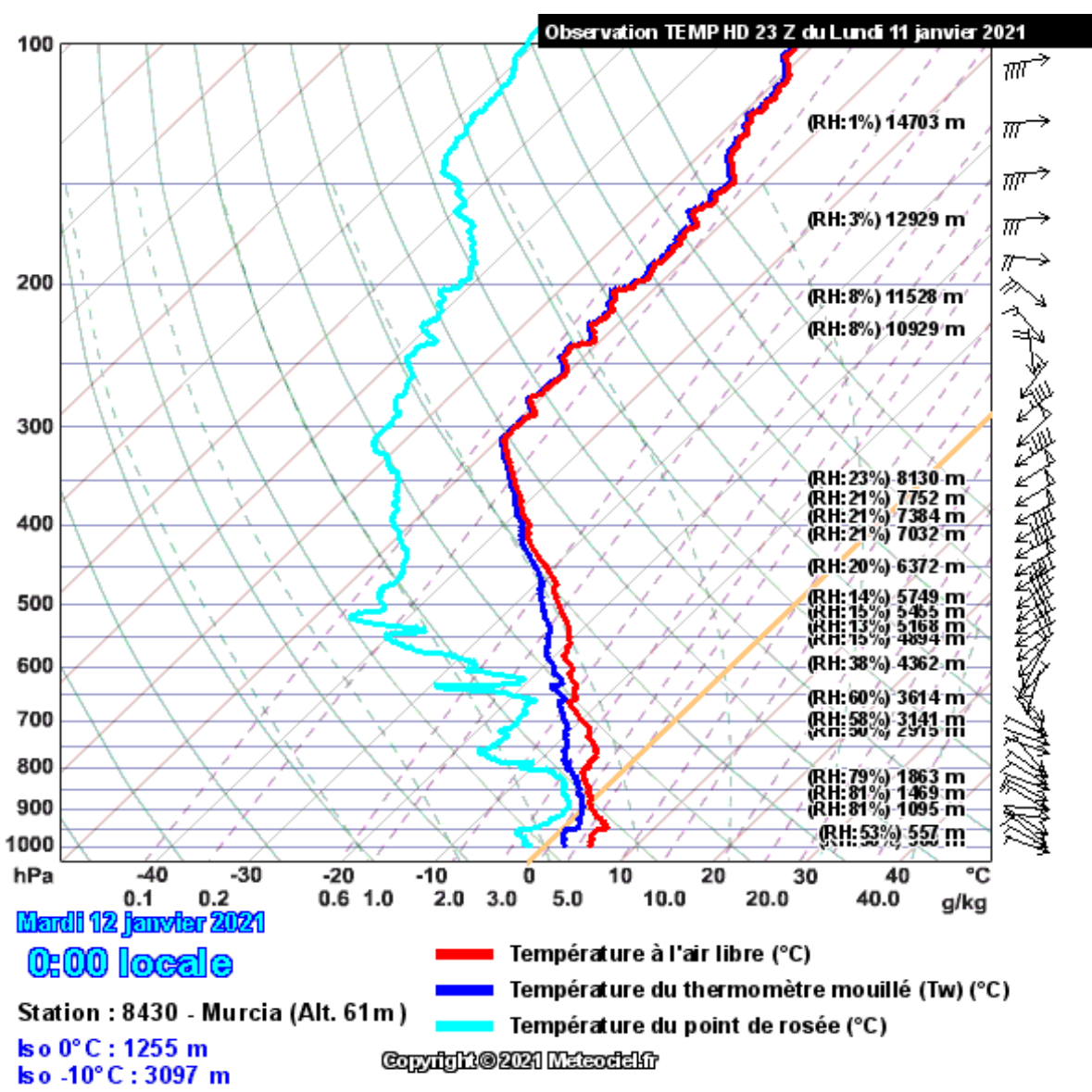

Fuente: meteociel.fr

Horas previas al 11 de enero de 2021, la retrotrayectoria de las masas de aire muestra una procedencia sinóptica de origen ártico marítimo (Am). En niveles altos atmosféricos (500 hPa), a unos 5500 m de altitud, la masa fría tiene su origen sinóptico entre la isla de Buffin (Canadá) y el este de Groenlandia. Sin embargo, en niveles atmosféricos inferiores, entre 750 y $900 \mathrm{hPa}$ (2500 a 1000 m de altitud), la procedencia muestra un origen próximo a la Península Ibérica, con una masa de aire que se ha sobreenfriado sobre su vertical. La masa de aire a unos 1500 m de altitud experimenta una trayectoria desde el norte del mar Cantábrico hasta el sur de la 
Península Ibérica. La evolución de la masa de aire muestra un ascenso altitudinal, reflejando la pérdida de temperatura en la columna atmosférica durante los días anteriores al episodio analizado (Figura 14).

El sondeo termodinámico lanzado el 12 de enero de 2021, a las 00 h UTC, en la ciudad de Murcia (Figura 15), muestra una importante masa de aire frío sobre la vertical del sureste de la Península Ibérica, con la isoterma de $0^{\circ} \mathrm{C}$ a una altitud de 1255 metros, y una temperatura de $1.5^{\circ} \mathrm{C}$ en el nivel geopotencial de $850 \mathrm{hPa}(1527 \mathrm{~m})$.

A pesar de que en niveles medios atmosféricos los valores higrométricos son elevados (8085\%), debido a la presencia de vientos húmedos de componente noroeste, el resto de columna (700-300 hPa) está caracterizada por una menor humedad relativa, especialmente en el nivel gepotencial de 500 hPa (10-15\%). Se trata, por tanto, de una masa de aire extremadamente seca en niveles medios-altos atmosféricos, como consecuencia del predominio de viento sinóptico de componente noreste desde 650 a 250 hPa (3620 a 10300 m), lo que repercutirá en un mayor descenso de las temperaturas mínimas en jornadas posteriores en el área de estudio.

Las clases de estabilidad de Pasquill reflejan un periodo estable del 11 al 19 de enero de 2021, si bien es preciso matizar que las condiciones de total estabilidad, ideal para los intensos procesos de inversión térmica, se dan especialmente durante las madrugadas del 18 y 19 de enero, aunque con un menor potencial para registrar temperaturas mínimas extremas (menor influencia de la nieve fresca y columna atmosférica con temperaturas menos frías). Durante las jornadas más frías, y, por tanto, con mayor potencial para registrar temperaturas mínimas más bajas (12 y 13 de enero), el coeficiente de mezcla vertical (Kz) se sitúa entre 4,6 y 44,9 m²/s en las horas de madrugada, lo que permite catalogarlas como horas nocturnas estables, pero no al nivel de las jornadas del 18 y 19 de enero, con valores de 0,34 a 0,87 m²/s. La agitación o turbulencia de la capa límite (Zi) es ostensiblemente menor durante los últimos días del episodio. En general, la capa límite se sitúa en altitudes muy bajas durante todo el episodio (50-53,9 m), incrementando, por tanto, la intensidad de los procesos de inversión térmica nocturna.

La madrugada más fría en el Calar de Hernán Pelea y Cabrilla es la del 12 de enero, una vez las condiciones inestables dejan paso a una atmósfera más tranquila durante las horas nocturnas. La presencia de una masa de aire fría (valores térmicos negativos en el nivel geopotencial de 850 $\mathrm{hPa}$ ), generó temperaturas inferiores a $0^{\circ} \mathrm{C}$ durante las horas diurnas. El efecto albedo de la nieve fresca caída recientemente en las horas anteriores fue clave para un mayor descenso térmico. 
Figura 16. Termografía $\left({ }^{\circ} \mathrm{C}\right)$ elaborada a través de las imágenes del satélite VIIRS LST (Band I5) del 12 de enero de 2021

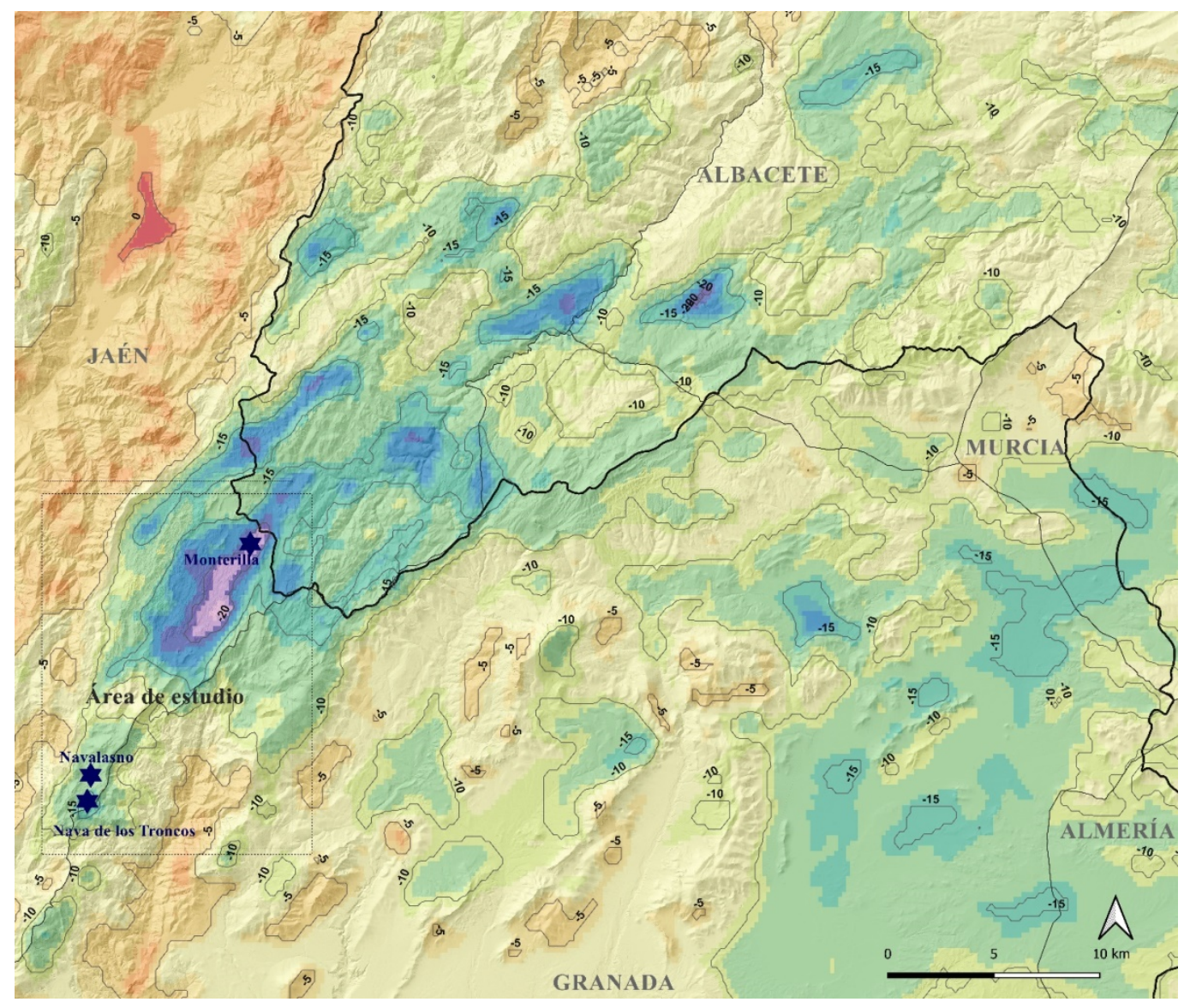

Fuente: elaboración propia a partir de worldview.earthdata.nasa.gov

En la madrugada del día 12 de enero se produce un descenso térmico muy notable en el paraje de la Nava de los Troncos, con un descenso térmico desde $-9,1^{\circ} \mathrm{C}$ a las 00.02 horas a $-20,6^{\circ} \mathrm{C}$ a las 2.22 horas. Posteriormente, la temperatura mínima absoluta alcanza $-28,8^{\circ} \mathrm{C}$, a las 7.32 horas, constituyendo el valor más bajo registrado en la mitad sur peninsular

Las temperaturas estimadas en el interior sureste peninsular en la madrugada del 12 de enero descienden en amplios sectores de $-10^{\circ} \mathrm{C}$, aunque son los calares del área de estudio los que destacan notablemente $\left(<20^{\circ} \mathrm{C}\right)$, si bien la estimación térmica en el área de estudio muestra sus limitaciones, especialmente en el Calar de la Cabrilla. Esto es debido a la menor extensión de las piscinas de aire frío y a la imposibilidad de que la resolución espacial del producto Band 15 la pueda captar con suficiente precisión (Figura 16). 
Figura 17. Evolución térmica diezminutal $\left({ }^{\circ} \mathrm{C}\right)$ de los sensores ubicados en el área de estudio, en las jornadas del 10 al 19 de enero de 2021

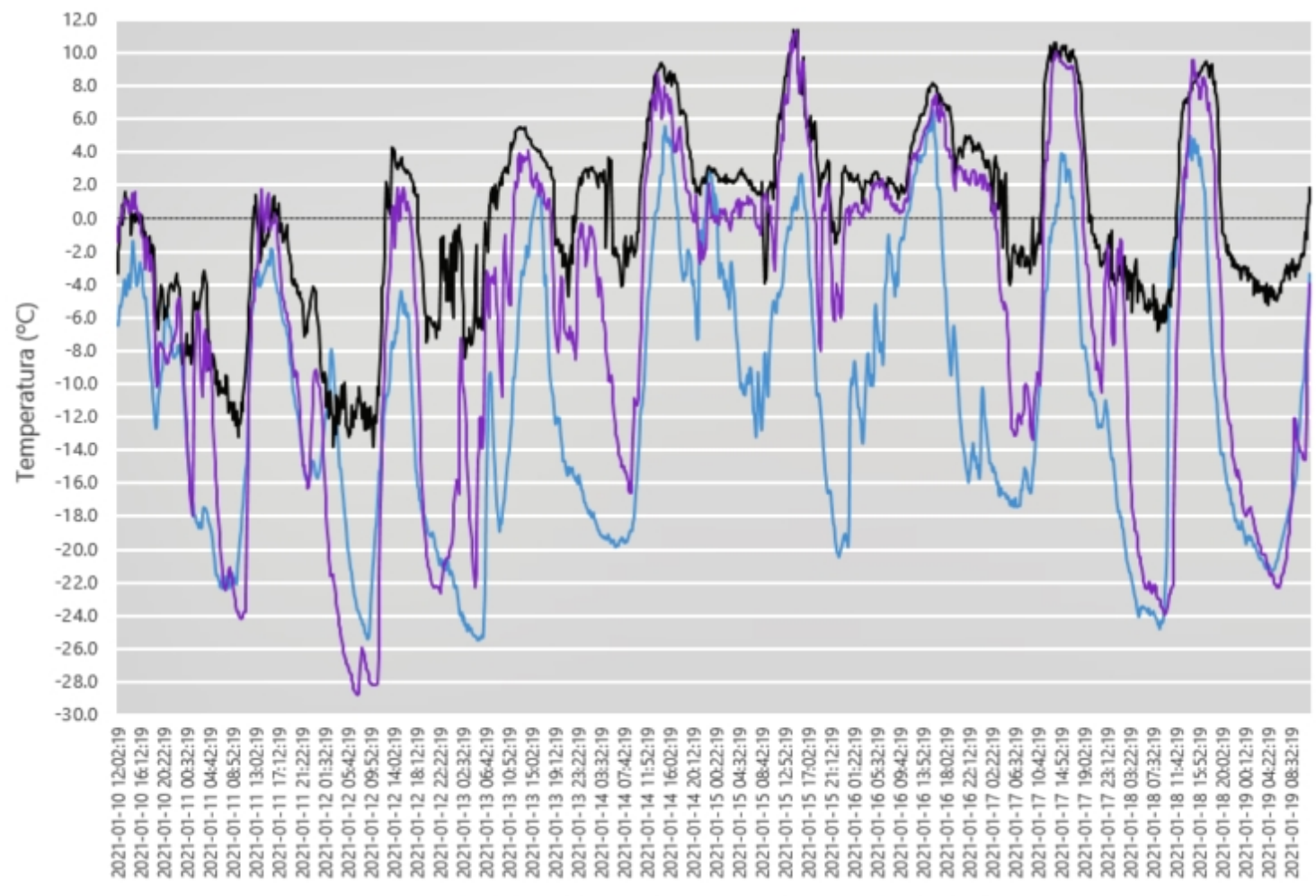

Don Fernando Navalasno - Nava de los Troncos

Fuente: elaboración propia

Durante el periodo del 11 al 19 de enero, el sector central de Hernán Pelea (Monterilla-Don Fernando) registra la temperatura media de las mínimas más baja del área de estudio, con un valor extraordinariamente bajo de $-21,3^{\circ} \mathrm{C}$, mientras que, a pesar de registrar la temperatura mínima absoluta, Nava de los Troncos-Polvo registra un promedio de las temperaturas mínimas algo superior $\left(-16,3^{\circ} \mathrm{C}\right)$, Esto es debido a la presencia de nubosidad nocturna en los sectores más elevados del área de estudio durante las jornadas del 15 y 16 de enero, según se aprecia en los reanálisis atmosféricos. La Figura 17 muestra, además, la muy probable aparición de una PCAP (piscina de aire frío persistente) en el corazón central de Monterilla-Don Fernando, con temperaturas máximas notablemente inferiores a las de los sectores más elevados, incluso inferiores a $-4^{\circ} \mathrm{C}$ el día 12 de enero. Finalmente, las madrugadas del 18 y 19 de enero, las de mayor estabilidad, registran un importante desplome térmico en horas nocturnas, con un tipo de CAP inalterada, de descenso limpio de la temperatura. En Nava de los Troncos se produce una caída desde $-1,3^{\circ} \mathrm{C}$ a las 1.38 horas de la madrugada, a $-20,5^{\circ} \mathrm{C}$ a las 4.58 horas, o lo que es lo mismo, un descenso de $19,2^{\circ} \mathrm{C}$ en 3 horas y 20 minutos. A pesar de que la masa de aire en niveles medios atmosféricos ( $850 \mathrm{hPa}$ ) es más templada, según el sondeo atmosférico de Murcia 
$\left(7,9^{\circ} \mathrm{C}\right)$, las temperaturas mínimas absolutas registradas descienden a $-24,8$ y $-23,9^{\circ} \mathrm{C}$, lo que supone una capacidad de inversión ( $\mathrm{C}_{\text {INV }}$ ) realmente importante, de $32,7^{\circ} \mathrm{C}$.

\section{Discusión y conclusiones}

Hace 75 años, las primeras mediciones de temperatura en Gstettneralm (Austria) revelaron la frecuente aparición de temperaturas mínimas extremadamente bajas en los fondos de dolinas (Schmidt, 1930). Durante las campañas de mediciones (1928-1942) se registraron varias veces valores mínimos inferiores a $-50^{\circ} \mathrm{C}$, y con recurrencia por debajo de $-35^{\circ} \mathrm{C}$. Resultó ser una característica bastante común en las noches claras de invierno, al igual que en la dolina de Peter Sink (EE. UU) donde en varias ocasiones las temperaturas han descendido de $-50^{\circ} \mathrm{C}$ (Zängl, 2005).

Los extremos térmicos mensuales registrados en el área de estudio, con temperaturas mínimas absolutas de $-28.8^{\circ} \mathrm{C}$ (Figura 3), suponen valores mínimos excepcionalmente fríos, y que, hasta la fecha, no habían sido registradas instrumentalmente por ningún observatorio meteorológico oficial en el sur de la Península lbérica. Tan solo la temperatura mínima registrada en la estación de AEMET (8175) de la Base Aérea de Los Llanos (Albacete), con -24 C el 3 de enero de 1971, puede equipararse a los registros alcanzados, si bien es cierto que en un rango temporal mucho más amplio.

Durante las últimas décadas, el estudio de las piscinas de aire frío en áreas montañosas ha sido posible gracias al avance de la tecnología, especialmente con la implementación de redes propias de termómetros registradores. El avance reciente en el desarrollo de los sensores ha permitido que sean lo suficientemente económicos, robustos y fiables para investigaciones científicas rigurosas. Tal y como han llevado a cabo diferentes investigaciones, como la de Whiteman (2000), se realizan comprobaciones y validaciones de los sensores en organismos meteorológicos oficiales, determinando una desviación de $0.26^{\circ} \mathrm{C}$ en los sensores $\mathrm{HOBO} \mathrm{H} 8$. Se trata de resultados similares a los obtenidos en la presente investigación, con una desviación de $0.2^{\circ} \mathrm{C}$ en las temperaturas mínimas. Los termómetros registradores, por tanto, parecen ser adecuados para una gran variedad de aplicaciones meteorológicas, y se utilizan de forma asidua durante los últimos años.

Además, en las últimas décadas, la proliferación de redes meteorológicas de aficionados, representadas por asociaciones y proyectos nacionales (ACAMET, AVAMET, AMETSE, NOROMET, FROSTSEI), ha supuesto la ampliación de los datos observacionales a ámbitos 
montañosos con importantes lagunas termo-pluviométricas. En ese sentido, el proyecto miniMET de la Agencia Estatal de Meteorología (AEMET) ha sido propuesto recientemente para proporcionar estaciones automáticas abiertas a los colaboradores o cualquier aficionado a la meteorología (Asanza, 2018). El avance de las nuevas tecnologías con la mejora en la precisión de las nuevas estaciones meteorológicas no profesionales, así como de los termómetros registradores, y la formación de los aficionados a la meteorología, ofrecen un nuevo impulso al BNDC (Banco Nacional de Datos Climatológicos) de AEMET, en el que progresivamente habría de integrar en próximos años los datos meteorológicos de aficionados (Nuñez Mora, 2010).

Los datos térmicos absolutos que arroja el área de estudio durante los últimos años contienen el registro de temperatura mínima más bajo registrado en época instrumental en la mitad sur peninsular, superando los $-26.0^{\circ} \mathrm{C}$ registrados el 3 de enero de 1971 en San Bartolomé (Munera, Albacete) (AEMET). Los valores se muestran muy por debajo de los de alguna de las capitales de provincia más frías de España $\left(-1,3^{\circ} \mathrm{C}\right.$ en Teruel, $-0,7^{\circ} \mathrm{C}$ en Ávila $0-0,6^{\circ} \mathrm{C}$ en Soria) (1981-2010), e incluso de los observatorios más fríos de la Península lbérica, en las provincias de Teruel y Guadalajara (jiloca, $-3,2^{\circ} \mathrm{C}$; Molina de Aragón, -2, $6^{\circ} \mathrm{C}$; o Calamocha, -2,3ㄷ) (Aupí, 2013). Se trata de valores excepcionalmente elevados a nivel peninsular. El estudio de Martínez Núñez et al. (2015) sobre heladas y horas de frío en la España peninsular (2002-2012) estima entre 1000 y 1500 horas de helada anual en varios sectores de las Cuencas del Duero y del Júcar, especialmente en los polos fríos de las provincias de Teruel, Guadalajara, Cuenca, Soria, Burgos, Ávila y Segovia. Los valores superan las 1500 horas, rangos parecidos a los del Calar de Hernán Pelea, en sectores muy localizados de la Cordillera Cantábrica (León y Palencia), en la Ibérica (Soria y Burgos) y en el Sistema Central (Segovia y Ávila). Sólo los Pirineos registran más de 2000 horas de helada al año. Para poner en contexto este valor, es preciso compararlo con los de los observatorios meteorológicos más fríos de Castilla y León (Nafría et al., 2013), donde el periodo libre de heladas alcanza 134 días en Almazán (Soria), 151 en Navarredonda de Gredos (Ávila), o 153 en la Puebla de Sanabria (Zamora).

Los resultados anteriores, especialmente relevantes en la mitad sur peninsular han sido registrados encorto intervalo temporal de 5 inviernos de observación, lo que contribuye de forma muy notable a la mejora del conocimiento del clima del sureste de la Península Ibérica. El registro, con la calibración del sensor térmico, y medido con una garita protectora de tipo pagoda cedida por AEMET, supone un acercamiento a la inclusión de este tipo de registros al BNDC de AEMET, si bien, todavía no es efectivo debido a la imposibilidad de validar las 
condiciones, principalmente de altura respecto a la superficie nevada, en el que fue tomado el registro.

Las lecturas de los 3 registradores de temperatura en los calares de Hernán Pelea y La Cabrilla han permitido identificar con gran precisión la distribución espacial de las temperaturas, y el comportamiento de las piscinas de aire frío (CAP). Estas aparecen en el área de estudio en el $52.2 \%$ de las madrugadas anuales. Se trata de registros similares a los aportados en el análisis de Conangla et al. (2018) en el Pirineo oriental, con casi el 60 \%; a los aportados por JemmettSmith et al., (2018) en Clun Valley (Reino Unido), con algo más del 60 \% en meses invernales, y finalmente superior al poco más del 35 \% en el valle de La Brevine (Suiza) (Vitasse et al., 2017).

Los fenómenos de piscinas de aire (CAP) sobre depresiones cerradas orográficamente generan gradientes térmicos muy notables con el reborde de los cerramientos. El aire que está en contacto con la superficie nevada se enfría muy rápidamente (notablemente más que el aire de su entorno), y al ser más denso y pesado fluye ladera abajo por su propio peso hasta depositarse en los fondos de valle sin escapatoria. Durante la madrugada se producen diferentes ciclos de enfriamiento que provoca constantemente que la temperatura vaya descendiendo hasta alcanzar valores muy extremos al final de la madrugada

En los Pirineos, la formación de las CAP comienza aproximadamente 1 hora después de la puesta del sol (Miró et al., 2010), mientras que en el área de estudio las de tipo inalterado dan comienzo a las 18.43 horas (muy tempranas). Las CAP se desarrollan bajo elevados gradientes de presión sinópticos, como reflejan los valores de capacidad de inversión ( $\left.\mathrm{C}_{\mathbb{I N V}}\right)$ superiores a $30^{\circ} \mathrm{C}$. Tales diferencias se producen, en general, bajo una masa de aire muy seca en niveles medios-altos atmosféricos, tal y como reflejan los valores higrométricos del área de estudio del 23 al $39 \%$ en los geopotenciales de 300 a 700 hPa. Este aspecto ya fue corroborado por Vihma et al., (2011), donde los estratos secos en niveles medios-altos atmosféricos favorecen las inversiones de temperatura intensas y delgadas.

El análisis efectuado en una cuenca semicerrada de Sierra Gorda (desierto de Atacama, Chile) muestra una intensa CAP que refleja una intensa inversión térmica potencial nocturna (18 K en $150 \mathrm{~m}$ ) y un rango de temperatura diurna de $30^{\circ} \mathrm{C}$ (Flores et al., 2020). Los autores muestran que las mayores concentraciones de polvo se observan dentro de la CAP, por debajo de la inversión de cobertura. Esto demuestra la importancia de la investigación de procesos de estabilidad en la dispersión de contaminantes y aerosoles. 
La importancia del estudio de las CAP ha sido demostrada recientemente por Kelsey et al. (2019), quienes determinan que la formación de vientos catabáticos y la acumulación de aire frío en valles montañosos afectan a la calidad del aire, tipo de precipitación y funciones del ecosistema local (bosque maduro de frondosas mixtas). La monitorización térmica pionera en ámbitos remotos, como los calares de la Cabrilla y Hernán Pelea, ha supuesto la identificación de temperaturas anormalmente frías, que bien pueden contribuir a la modificación del ecosistema local, y que abre, por tanto, una nueva vía de estudio en la zona.

Los procesos de ITN presentan mayor intensidad de inversión a medida que la capa límite (Zi) posee menos altura y el coeficiente de mezcla vertical (Kz) presenta una menor agitación, con velocidad más baja. La naturaleza poco profunda de la capa límite de la piscina de aire frío da como resultado una mayor sensibilidad de las variables meteorológicas cercanas a la superficie, lo que genera importantes procesos de subsidencia con inversiones de temperatura muy marcadas (Murthy \& Varghese 2004; Foster at al., 2017). Se produce, por tanto, un potente hundimiento a escala sinóptica que contribuye a la formación de intensas inversiones, con gradientes de presión muy débiles, y una disminución del punto de rocío con la altura, tal y como ocurre en Grecia (Kassomenos et al., 2014).

Investigaciones anteriores sugieren que los vientos por encima de la capa de ITN deben aumentar de velocidad para continuar el proceso de erosión (Petkovsek, 1992; Rakovec et al., 2002; Zhong et al., 2003). Este tipo de CAP se caracteriza por presentar una importante variabilidad en la evolución de la temperatura a lo largo de las horas nocturnas, especialmente en aquellos emplazamientos situados a mayor altitud. El incremento de la velocidad del viento suele ser la principal causa que evita el descenso inalterado de la temperatura, aunque no son valores elevados, si no, se produciría la rotura del estrato de ITN. Suele estar asociado al paso de alguna línea de inestabilidad o pequeña perturbación

Se trata de configuraciones sinópticas con escaso flujo de viento y baja humedad relativa (lacobellis et al., 2009), caracterizadas por crestas anticiclónicas a gran escala (Bailey, 2011). Las condiciones de flujo a gran escala para los extremos fríos son similares en muchos lugares de Europa, con anomalías de bloqueo sobre el Atlántico norte y el norte de Europa, que contribuyen notablemente a la advección de masas de aire frío (Pfahl, 2014). Los extremos fríos invernales sobre Europa y el sureste de Estados Unidos se explican principalmente por el bloqueo anómalo asociado con episodios persistentes de fase negativa de gran amplitud de la NAO (Guirguis et al., 2011). 
Se identifican dos factores principales asociados a los eventos fríos extremos según Zhou et al., (2009), que se asemejan a las conclusiones aportadas en la investigación:

- Bloqueo persistente al oeste del área de afección, que permanece casi estacionario durante varias jornadas, provocando la advección de aire seco y frío.

- Capa de inversión profunda en la troposfera inferior asociada con una capa de nieve de gran extensión.

Sauberer \& Dirmhirn $(1954,1956)$ ya encontraron importantes correlaciones entre el espesor de nieve fresca y un mayor descenso térmico en zonas de valle. Encontraron diferencias térmicas entre el fondo de una dolina y las ubicaciones a lo largo de las pendientes laterales por encima del flujo de salida más bajo que oscilaban entre 25 y $30^{\circ} \mathrm{C}$ en presencia de nieve recién caída, mientras que, las diferencias descendían a 10 y $15^{\circ} \mathrm{C}$ con ausencia de nieve. La capa de nieve es un factor importante que influye en la velocidad de enfriamiento y, por tanto, en la intensidad de la inversión.

Además de las características orográficas del área de estudio, la sequedad de la masa de aire, con bajos valores higrométricos, parece explicar este aspecto. A menor humedad relativa, la capacidad de inversión térmica aumenta (coeficiente de correlación R2 del 0.68) (Figura 12b). Los valores de CINV superiores a $12^{\circ} \mathrm{C}$ se registran con valores higrométricos muy bajos (entre 20 y $40 \%)$.

Las piscinas de aire frío persistentes (PCAP) a menudo se pronostican mal mediante los modelos de predicción numérica de mesoescala, debido en parte a la inadecuada parametrización física de la capa limita planetaria, y también a la resolución espacial de la superficie del terreno. Crosman \& Horel (2017) determinan que el modelo WRF LES de 250 m fue capaz de simular la evolución y erosión turbulenta de la piscina fría, al igual que el WRF ARW, que fue capaz de simular un evento de PCAP en el valle del río Arve (Alpes franceses) (Arduini et al., 2020). La mejora en la predicción de las CAP abre una línea de investigación en la meteorología operativa (Sun et al., 2020).

Finalmente, entre los resultados más concluyentes:

- Las temperaturas mínimas absolutas registradas en el área de estudio $\left(-28.8^{\circ} \mathrm{C}\right)$ constituyen los valores más bajos desde que hay series observacionales en la mitad sur peninsular. La regularidad anual es manifiesta, con temperaturas medias de las mínimas absolutas de $-19.9^{\circ} \mathrm{C}$ en la Nava del Polvo. 
- El tipo de CAP más representativo corresponde al de erosión turbulenta (39,0\%), confirmando que los inviernos en el área de estudio presentan una gran agitación atmosférica. El $2^{\circ}$ tipo es el de perturbación alta, un tipo turbulento que afecta a la evolución de la temperatura en los sensores ubicados a una mayor altitud $(29,1 \%)$. A pesar de no predominar los procesos de evolución inalterada (los más estables), los desplomes térmicos son muy relevantes.

- La configuración sinóptica que da lugar a los registros extremos de temperatura mínima muestra una vaguada polar continental de onda corta en el nivel geopotencial de $500 \mathrm{hPa}$. Genera la advección de una masa de aire frío en niveles medios-altos atmosféricos con una anomalía de temperatura de entre $-2 /-3^{\circ} \mathrm{C}$ respecto a lo habitual en periodo invernal.

Agradecimientos: Especial agradecimiento a la Delegación Territorial de Murcia de la Agencia Estatal de Meteorología (AEMET) por la cesión de dos garitas meteorológicas de tipo pagoda, y por la calibración de los termómetros registradores utilizados.

Declaración responsable: Los autores declaran que no existe ningún conflicto de interés con relación a la publicación de este artículo. Las tareas se han distribuido de la siguiente manera: el artículo ha sido coordinado por D. Espín. Él ha llevado a cabo la puesta en marcha de la Red propia de termómetros registradores, y lo ha gestionado junto a C. Conesa. J. Olcina; C. Conesa y D. Espín han participado en la revisión bibliográfica y redacción del artículo. Finalmente J. Olcina ha coordinado las propuestas elaboradas en el apartado de configuración sinóptica y análisis de la situación atmosférica del episodio frío del 11-19 de enero de 2021. 


\section{Bibliografía}

Agencia Estatal de Meteorología (2021). Informe sobre el episodio meteorológico de fuertes nevadas y precipitaciones ocasionadas por borrasca Filomena y posterior ola de frío. Ministerio para la transición ecológica y el reto demográfico. Retrieved from https://www.aemet.es/documentos/es/conocermas/recursos_en_linea/publicaciones_y estudios/estudios/Informe_episodio_filomena.pdf

Arduini, G., Chemel, C., \& Staquet, C. (2020). Local and non-local controls on a persistent coldair pool in the Arve River Valley. Quarterly Journal of the Royal Meteorological Society, 146(731), 2497-2521. https://doi.org/10.1002/aj.3776

Asanza, F. (2018). Project AEMET miniMET. Acta de las Jornadas Científicas de la Asociación Meteorológica Española, 1(35). https://doi.org/10.30859/ameJrCn35p34

Aupí, V. (2013). El triángulo de hielo. Dobleuve Comunicación.

Barr, S., \& Orgill, M. (1989). Influence of external meteorology on nocturnal valley drainage winds. Journal of Applied Meteorology, 28(6), 497-517. https://doi.org/10.1175/15200450(1989)028<0497:IOEMON>2.0.CO;2

Bailey, A.; Chase, T. N.; Cassano, J.J., \& Noone, D. (2011). Changing Temperature Inversion Characteristics in the U.S. Southwest and Relationships to Large-Scale Atmospheric Circulation. Journal of Applied Meteorology and Climatology, 50, 13071323. https://doi.org/10.1175/2011JAMC2584.1

Biernat, K. A., Bosart, L. F., \& Keyser, D. (2021). A climatological analysis of the linkages between tropopause polar vortices, cold pools, and cold air outbreaks over the central and eastern United States. Monthly Weather Review, 149(1), 189206. https://doi.org/10.1175/MWR-D-20-0191.1

Clements, C.B., Whiteman, C.D., \& Horel, J.D. (2003). Cold-air-pool structure and evolution in a mountain basin: Peter Sinks, Utah. Journal of Applied Meteorology, 42(6), 752 768. https://doi.org/10.1175/1520-0450(2003)042<0752:CSAEIA>2.0.CO;2

Colgan, S., Sun, X., \& Holmes, H. (2019, December). A Review of Cold Air Pool Events in the Intermountain West using Radiosondes and the North American Mesoscale Model (NAM). In AGU Fall Meeting Abstracts (pp. A510-2861). 
Conangla, L., Cuxart, J., Jiménez, M. A., Martínez-Villagrasa, D., Miró, J. R., Tabarelli, D., \& Zardi, D. (2018). Cold-air pool evolution in a wide Pyrenean valley. International Journal of Climatology, 38(6), 2852-2865. https://doi.org/10.1002/joc.5467

Crosman, E. T., \& Horel, J. D. (2017). Large-eddy simulations of a Salt Lake Valley cold-air pool. Atmospheric Research, 193, 10-25. https://doi.org/10.1016/j.atmosres.2017.04.010

Dorninger, M., Whiteman, C.D., Bica, B., Eisenbach, S., Pospichal, B., \& Steinacker, R. (2011). Meteorological events affecting cold-air pools in a small basin. Journal of Applied Meteorology and Climatology, 50(11), 2223-2234. https://doi.org/10.1175/2011|AMC2681.1

Eisenbach, S., Pospichal, B., Whiteman, C.D., Steinacker, R., \& Dorninger, M. (2003). Classification of cold air pool events in the Gstettneralm, a sinkhole in the Eastern Alps. Extended Abstracts, Int. Conf. on Alpine Meteorology and MAP-Meeting, Brig, Switzerland, MeteoSwiss, Publication 66, 157-160.

Espín Sánchez, D., \& Conesa García, C. (2018). Estudio comparativo del calor extremo entre el Valle del Guadalquivir y las Vegas del Segura: tendencia y cartografía de alta resolución. Revista de Estudios Andaluces, 36, 1-25. https://10.12795/rea.2018.i36.01

Flores, F., Arriagada, A., Donoso, N., Martínez, A., Viscarra, A., Falvey, M., \& Schmitz, R. (2020). Investigation of a Nocturnal Cold-Air Pool in a Semiclosed Basin Located in the Atacama Desert. Journal of Applied Meteorology and Climatology, 59(12), 19531970. https://doi.org/10.1175/JAMC-D-19-0237.1

Foster, C.S., Crosman, E.T., \& Horel, J.D (2017). Simulations of a Cold-Air Pool in Utah's Salt Lake Valley: Sensitivity to Land Use and Snow Cover. Boundary-Layer Meteorol, 164, 6387. https://doi.org/10.1007/s10546-017-0240-7

Fritts, D. C., Bizon, C., Werne, J. A., \& Meyer, C. K. (2003). Layering accompanying turbulence generation due to shear instability and gravity-wave breaking. Journal Geophysical Research, 108, 8452. https://doi.org/10.1029/2002JD002406

Gómez Zotano, J., Alcántara-Manzanares, J., Martínez-lbarra, E., \& Olmedo-Cobo, J. A. (2015). La sistematización del clima mediterráneo: identificación, clasificación y caracterización climática de Andalucía (España). Revista de Geografía Norte Grande, 61, 161 180. http://dx.doi.org/10.4067/S0718-34022015000200009 
Gómez Zotano, J., Alcántara-Manzanares, J., Martínez-lbarra, E., \& Olmedo-Cobo, J. A. (2016). Applying the technique of image classification to climate science: the case of Andalusia (Spain). Geographical Research, 54(4), 461-470 https://doi.org/10.1111/1745-5871.12180

Grudzielanek, A. M., \& Fliegner, M. (2018). Cold-air pool analyses in the Funtensee basin (Berchtesgaden Alps) using thermal imaging. In EGU General Assembly Conference Abstracts (p. 9444).

Gudiksen, P. H., Leone Jr, J. M., King, C. W., Ruffieux, D., \& Neff, W. D. (1992). Measurements and modeling of the effects of ambient meteorology on nocturnal drainage flows. Journal of Applied Meteorology, 37(9), 1023-1032. https://doi.org/10.1175/15200450(1992)031<1023:MAMOTE>2.0.CO;2

Guirguis, K., Gershunov, A., Schwartz, R., \& Bennett, S. (2011). Recent warm and cold daily winter temperature extremes in the Northern Hemisphere. Geophysical Research Letters, 38(17). https://doi.org/10.1029/2011GL048762

Iglesias González, M., Acuña, J.L, García H., Rodríguez, A., Pajares, S., Rodríguez, J., RuizVerdú, A., \& Jesús Pérez H. (2018). Proyecto Jous: temperaturas mínimas absolutas en la cordillera cantábrica y su relación con las piscinas de aire frío. In XXXV Jornadas científicas de la AME-19 $9^{\circ}$ encuentro hispano-luso de meteorología (p. 218). https://doi.org/10.30859/ame/rCn35

Jemmett-Smith, B., Ross, A. N., \& Sheridan, P. (2018). A short climatological study of cold air pools and drainage flows in small valleys. Weather, 73(8), 256262. https://doi.org/10.1002/wea.3281

Kassomenos, P. A., Paschalidou, A. K., Lykoudis, S., \& Koletsis, I. (2014). Temperature inversion characteristics in relation to synoptic circulation above Athens, Greece. Environmental monitoring and assessment, 186(6), 3495-3502. https://doi.org/10.1007/s10661-014-3632-x

Kelsey, E. P., Cann, M. D., Lupo, K. M., \& Haddad, L. J. (2019). Synoptic to Microscale Processes Affecting the Evolution of a Cold-Air Pool in a Northern New England Forested Mountain Valley. Journal of Applied Meteorology and Climatology, 58(6), 13091324. https://doi.org/10.1175/JAMC-D-17-0329.1

Kendall, M. G. (1938). A new measure of rank correlation. Biometrika, 30(1/2), 81-93. 
Lareau, N. P., Crosman, E., Whiteman, C. D., Horel, J. D., Hoch, S. W., Brown, W. O., \& Horst, T. W. (2013). The persistent cold-air pool study. Bulletin of the American Meteorological Society, 94(1), 51-63. https://doi.org/10.1175/BAMS-D-11-00255.1

Litschauer, D. (1962). Untersuchung der Entwicklung von Kaltluftseen in Dolinen- und Beckenlagen [Investigation of the development of cool air pools in sinkholes and basins] (Doctoral dissertation, University of Vienna).

Martínez Núñez, L., Moreno, J. V., Chazarra, A., Gallego Abaroa, T., Avello, E., \& Botey, M. R. (2015). Mapas de riesgo: Heladas y horas de frío en la España peninsular (periodo 20022012). Agencia Estatal de Meteorología (España).

McCaffrey, K., Wilczak, J. M., Bianco, L., Grimit, E., Sharp, J., Banta, R., \& Muradyan, P. (2019). Identification and characterization of persistent cold pool events from temperature and wind profilers in the Columbia River Basin. Journal of Applied Meteorology and Climatology, 58(12), 2533-2551. https://doi.org/10.1175/JAMC-D-19-0046.1

Miró, J. R., Pagès, M., \& Kossman, M. (2010). Cold-air pool detection tools in the Pyrenees valleys. In 14th Conference on Mountain Meteorology. Squaw Valley, CA, United States, August 30-September 3. Retrieved from

https://ams.confex.com/ams/14MountMet/webprogram/Paper173620.html

Mucha, M. (2021, January 16). -35,8 grados: El récord del paleoclimatólogo Miguel y sus piscinas del frío en la España siberiana. In El Mundo. https://www.elmundo.es/cronica/2021/01/16/6001ea9ffc6c83e77e8b46ae.html

Muñoz, R. C., \& Armi, L. (2020). The Raco Wind in Central Chile: A Recurring Gap Flow Interacting with a Cold Air Pool. In 19th Conference on Mountain Meteorology. Park City, UT, United States, July Retrieved from https://ams.confex.com/ams/19Mountain/webprogram/Paper376301.html

Murthy, A. V., \& Varghese, S (2004). Nocturnal Temperature Inversions Under Calm Clear Conditions. In Mechanics of the 21st century (Proceedings of the 21st International Congress of Theoretical and Applied Mechanics). Warsaw, Poland, August 15-21.

Nafría, D. A., Garrido, N., Álvarez, M. V., Cubero, D., Fernández, M., Villarino, I., \& Abia, I. (2013). Atlas Agroclimático de Castilla y León. Madrid: Instituto Tecnológico Agrario de Castilla y León y Agencia Estatal de Meteorología. 
Neff, W. D., \& King, C. W. (1989). The accumulation and pooling of drainage flows in a large basin. Journal of Applied Meteorology, 28(6), 518-529. https://doi.org/10.1175/15200450(1989)028<0518:TAAPOD>2.0.CO;2

Núñez Mora, J. Á. (2010). Las nuevas redes de datos meteorológicos. Agencia Estatal de Meteorología.

OMM (2017). Manual del Sistema Mundial de Observación Volumen I - Aspectos mundiales. Organización Meteorológica Mundial.

Pasquill, F. (1961). The estimation of the dispersion of windborne material. Metereology Magazine, (90), 33.

Petkovšek, Z. (1992). Turbulent dissipation of cold air lake in a basin. Meteorology and Atmospheric Physics, 47(2-4), 237-245. https://doi.org/10.1007/BF01025620

Pfahl, S. (2014). Characterising the relationship between weather extremes in Europe and synoptic circulation features. Natural Hazards and Earth System Sciences, 14(6), 1461 1475. https://doi.org/10.5194/nhess-14-1461-2014

Pospichal, B., Eisenbach, S., Whiteman, C.D., Steinacker, R., \& Dorninger, M. (2003). Observations of the cold air outflow from a basin cold pool through a low pass. In Extensive Abstract, vol. A. (pp. 153-156). International Conference on Alpine Metereology and the MAPMeeting Brig, Switzerland, May 19-23.

Prandtl, L. (1904). Über Flüssigkeitsbewegung bei sehr kleiner Reibung. Verhandlungen des Dritten Internationalen Mathematiker-Kongresses in Heidelberg 1904 (pp. 484-491). Leipzig: ed. Teubner.

Renon, B. (2011). Le fabbriche naturali del freddo. Dipartimento Regionale per la Sicurezza del Territorio. ARPAV.

Sauberer, F., \& Dirmhirn, I. (1956). Weitere Untersuchungen über die kaltluftansammungen in der Doline Gstettner-Alm bei Lunz im Niederösterreich (Further investigations of the cold air buildup in the Gstettner-Alm doline near Lunz in lower Austria). Wetter Leben, (8), 187-196.

Scherhag, R. (1948). Neue Methoden des Wetteranalyse und Wetterprognose. Springer Verlag Berlin, (179), 227-235. 
Schmidt, E., \& Beckmann, W. (1930). Das Temperatur-und Geschwindigkeitsfeld vor einer Wärme abgebenden senkrechten Platte bei natürlicher Konvektion. Technische Mechanik und Thermodynamik, 1(11), 391-406. https://doi.org/10.1007/BF02660553

Schmidt, E., \& Beckmann, W. (1930). Das Temperatur-und Geschwindigkeitsfeld vor einer Wärme abgebenden senkrechten Platte bei natürlicher Konvektion. Technische Mechanik und Thermodynamik, 1(11), 391-406. https://doi.org/10.1007/BF02660553

Sun, X., Holmes, H. A., \& Xiao, H. (2020). Surface Turbulent Fluxes during Persistent Cold-Air Pool Events in the Salt Lake Valley, Utah. Part II: Simulations. Journal of Applied Meteorology and Climatology, 59(6), 1029-1050. https://doi.org/10.1175/JAMC-D-19-0053.1

Vihma, T., Kilpeläinen, T., Manninen, M., Sjöblom, A., Jakobson, E., Palo, T., Jaagus, J., \& Maturilli, M. (2011). Characteristics of Temperature and Humidity Inversions and Low-Level Jets over Svalbard Fjords in Spring. Advances in Meteorology. https://doi.org/10.1155/2011/486807

Vitasse, Y., Klein, G., Kirchner, J. W., \& Rebetez, M. (2017). Intensity, frequency and spatial configuration of winter temperature inversions in the closed La Brevine valley, Switzerland. Theoretical and Applied Climatology, 130(3), 1073-1083. https://doi.org/10.1007/s00704$\underline{016-1944-1}$

Vrhovec, T., \& Hrabar, A. (1996). Numerical simulations of dissipation of dry temperature inversions in basins. Geofizika, 13(1), 81-96. https://hrcak.srce.hr/18774

Whiteman, C. D., \& McKee, T. B. (1982). Breakup of temperature inversions in deep mountain valleys: Part II. Thermodynamic model. Journal of Applied Meteorology, 21(3), 290302. https://doi.org/10.1175/1520-0450(1982)021<0290:BOTIID>2.0.CO;2

Whiteman, C.D., (1986). Temperature inversion buildup in Colorado's Eagle Calley. Meteorology and Atmospheric Physics, 35(4), 220-226. https://doi.org/10.1007/BF01041814

Whiteman, C.D., \& Barr, S. (1986). Atmospheric mass transport by a long-valley wind systems in a deep Colorado valley. Journal of Climate and Applied Meteorology, 25(9), 1205 1212. https://doi.org/10.1175/1520-0450(1986)025<1205AMTBAV>2.0.CO;2

Whiteman, C.D., Bian, X., \& Zhong, S. (1997): Low-level jet climatology from enhanced rawinsonde observations at a site in the southern Great Plains. Journal of Applied Meteorology, 36(10): 1363-1376. https://doi.org/10.1175/1520-0450(1997)036<1363:LLJCFE>2.0.CO;2 
Whiteman, C. D. (2000). Mountain meteorology: fundamentals and applications. Oxford University Press.

Whiteman, C.D., Zhong, S., Shaw, W.J., Hubbe, J.M., Bian, X., \& Mittelstadt, J. (2001). Cold pools in the Columbia Basin. Weather and Forecasting, 16(4). 432447. https://doiorg/10.1175/1520-0434(2001)016<0432:CPITCB>2.0.CO;2

Whiteman, C.D., Pospichal, B., Eisenbach, S., Weihs, P., Clements, C.B., Steinacker, R., \& Dorninger, M (2004a). Inversion breakup in small Rocky Mountain and Alpine basins. Journal of Applied Meteorology, 43(8), 1069-1082. https://doi.org/10.1175/15200450(2004)043<1069:IBISRM>2.0.CO;2

Whiteman, C.D., Haiden, T., Pospichal, B., Eisenbach, S. \& Steinacker, R. (2004b). Minimum temperatures, diurnal temperature ranges, and temperature inversions in limestone sinkholes of different sizes and shapes. Journal of Applied Meteorology, 43(8), 1224 1236. https://doi.org/10.1175/1520-0450(2004)043<1224:MTDTRA>2.0.CO;2

Whiteman, C.D., Hoch, S.W., Hahnenberge R.M., Muschinski, A., Hohreiter, V., Behn, M., \& Clements, C.B. (2008). METCRAX 2006: Meteorological experiments in arizona's meteor crater. Bulletin of the American Meteorological Society, 89(11), 1665 1680. https://doi.org/10.1175/2008BAMS2574.1

Zängl, G. (2005). Formation of extreme cold-air pools in elevated sinkholes: An idealized numerical process study. Monthly Weather Review, 133(4), 925 941. https://doi.org/10.1175/MWR2895.1

Zhong, S., Bian, X., \& Whiteman, C. D. (2003). Time scale for cold-air pool breakup by turbulent erosion. Meteorologische Zeitschrift, 12(4), 229-233. https://doi.org/10.1127/0941$\underline{2948 / 2003 / 0012-0231}$

Zhong, S., Whiteman, C. D., Bian, X., Shaw, W. J., \& Hubbe, J. M. (2001). Meteorological processes affecting the evolution of a wintertime cold air pool in the Columbia basin. Monthly Weather Review, 129(10), 2600-2613. https://doi.org/10.1175/15200493(2001)129<2600:MPATEO>2.0.CO;2

Zhou, W., Chan, J. C., Chen, W., Ling, J., Pinto, J. G., \& Shao, Y. (2009). Synoptic-scale controls of persistent low temperature and icy weather over southern China in January 2008. Monthly Weather Review, 137(11), 3978-3991. https://doi.org/10.1175/2009MWR2952.1 